\title{
"Small Axonless Neurons": Postnatally Generated Neocortical Interneurons with Delayed Functional Maturation
}

\author{
Corentin Le Magueresse, ${ }^{1,4 \star}$ Julieta Alfonso, ${ }^{3,4 \star}$ Konstantin Khodosevich, ${ }^{1,4}$ Ángel A. Arroyo Martín, ${ }^{1,4}$ Christine Bark, ${ }^{2}$ \\ and Hannah Monyer ${ }^{1,4}$ \\ Departments of ${ }^{1}$ Clinical Neurobiology and ${ }^{2}$ Child Psychiatry, Heidelberg University Medical Center, D-69120 Heidelberg, Germany, ${ }^{3}$ Department of \\ Molecular Neuroscience, Max-Planck-Institute for Medical Research, D-69120 Heidelberg, Germany, and ${ }^{4}$ Department of Clinical Neurobiology/A230, \\ German Cancer Research Center, D-69120 Heidelberg, Germany
}

GABAergic interneurons of the mouse cortex are generated embryonically in the ventral telencephalon. Recent evidence, however, indicated that a subset of cortical cells expressing interneuronal markers originate in the neonatal subventricular zone. This has raised interest in the functional development and incorporation of these postnatally generated cells into cortical circuits. Here we demonstrate that these cells integrate in the cortex, and that they constitute two distinct GABAergic interneuronal classes. Whereas one class reflects the tail end of embryonic interneuron genesis, the other class comprises interneurons that are exclusively generated perinatally and postnatally. The latter constitute a novel subclass of interneurons. They are preferentially located in the deeper layers of the olfactory and orbital cortices, exhibit a unique firing pattern and slow functional maturation. Based on their distinct morphology we termed them "small axonless neurons" and indeed, unlike other cortical neurons, they communicate with their neuronal partners via dendrodendritic synapses. Finally, we provide evidence that the number of small axonless neurons is enhanced by odor enrichment, a further indication that they integrate into neural circuits and participate to olfactory processing.

\section{Introduction}

Most inhibitory interneurons in the mouse neocortex are generated in restricted areas of the embryonic ventral telencephalon, known as the ganglionic eminence and the preoptic area (Anderson et al., 1997; Marín and Rubenstein, 2003; Wonders and Anderson, 2006; Gelman et al., 2009). Genetic and fate-mapping studies have revealed that distinct subtypes of interneurons arise from different parts of the ganglionic eminence (Wichterle et al., 2001; Nery et al., 2002; Xu et al., 2004; Fogarty et al., 2007). For instance, the medial ganglionic eminence is the source of Martinotti cells, fast-spiking basket cells and chandelier cells, while progenitors from the caudal ganglionic eminence give rise to at least nine subtypes of cortical interneurons with distinct intrinsic

\footnotetext{
Received Aug. 19, 2011; accepted Sept. 8, 2011.

Author contributions: C.L.M., J.A., and H.M. designed research; C.L.M., J.A., K.K., A.A.A.M., and C.B. performed research; C.L.M., J.A., K.K., A.A.A.M., and C.B. analyzed data; C.L.M., J.A., and H.M. wrote the paper.

C.L.M. was supported by a Postdoctoral Grant from Medical Faculty Heidelberg. J.A. was supported by a Marie Curie Incoming International Fellowship. H.M. was supported by the Schilling Foundation, the Sonderforschungsbereich 488 (project D3, Maine 1985/1-1), and the European Union Synapse Grant LSHM-CT-2005-019055. We thank U. Amtmann, R. Hinz-Herkommer, and I. Preugschat-Gumprecht for expert technical assistance, H. Jaschonek, N. Arians, and E. Brinkmann for morphological reconstructions, F. H. Gage for retroviral plasmids, M. Sugita for the GFP-IRES-tWGA/DsRed construct, and P. Seeburg, J. von Engelhardt, and W. Kelsch for critical comments on this manuscript.

${ }^{*}$ C.L.M. and J.A. contributed equally,

The authors declare no competing financial interests.

Correspondence should be addressed to Hannah Monyer at the above address at the German Cancer Research Center. E-mail: h.monyer@dkfz-heidelberg.de.

DOI:10.1523/JNEUROSCI.4273-11.2011

Copyright $\odot 2011$ the authors $\quad 0270-6474 / 11 / 3116731-17 \$ 15.00 / 0$
}

electrophysiological and morphological properties that are positive for reelin or vasoactive intestinal polypeptide (Butt et al., 2005; Miyoshi et al., 2010).

Throughout postnatal development and adulthood, neurogenesis persists in two regions, the subventricular zone (SVZ) of the lateral ventricles and the subgranular layer (SGL) of the hippocampus (Altman and Das, 1965; Lois and Alvarez-Buylla, 1994; Lledo et al., 2008; Zhao et al., 2008; Pathania et al., 2010). New neurons generated in the SVZ migrate to the olfactory bulb via the rostral migratory stream (RMS), whereas those generated in the SGL are incorporated into the hippocampal dentate gyrus. Functional integration of newborn neurons into preexisting neuronal networks has been demonstrated in both structures (van Praag et al., 2002; Belluzzi et al., 2003; Carleton et al., 2003; Espósito et al., 2005; Toni et al., 2008).

We have recently described the generation of transgenic mice expressing the in vivo marker enhanced green fluorescent protein (EGFP) under the control of the $5 \mathrm{HT}_{3}$ receptor promoter $\left(5 \mathrm{HT}_{3}\right.$ EGFP mice). In these mice, during the first days after birth, numerous EGFP-expressing cells born in the SVZ exit the RMS and migrate to the cortex, where they express markers of GABAergic interneurons, suggesting that the postnatal SVZ is a source of cortical interneurons in rodents (Inta et al., 2008). The addition of new cortical EGFP-expressing cells born in the SVZ rapidly decreases during postnatal development and is virtually absent or barely detectable in adult mice. Evidence is still lacking that these cells acquire physiological neuronal properties and integrate into the already established cortical networks of young rodents. 
Here, we used injections of a retroviral vector into the SVZ of $5 \mathrm{HT}_{3}$-EGFP pups at postnatal day $4(\mathrm{P} 4)$ to express the red fluorescent protein (RFP) in newborn cells. This enabled subsequent functional characterization of postnatally generated cells of a defined age. The majority of postnatally born cells developed into small axonless interneurons, with delayed development of spiking activity. We compared the development of functional properties in postnatally generated $5 \mathrm{HT}_{3}$-EGFP neurons with the development in embryonically generated $5 \mathrm{HT}_{3}$-EGFP neurons, using in utero retrovirus-RFP injections. Major differences were observed in the characteristics and development of prenatally and postnatally generated neurons. Our results show that most cortical neurons born postnatally in the SVZ become small axonless neurons, a new subtype of cortical interneurons. These neurons become synaptically integrated into preestablished neocortical networks.

\section{Materials and Methods}

Postnatal labeling of newborn neurons in the SVZ. We used a replicationdeficient murine Moloney leukemia virus-based retroviral vector expressing RFP under the control of the CAG promoter, kindly provided by Dr. F. H. Gage (Salk Institute). The concentrated viral solution $\left(10^{8}\right.$ $\mathrm{cfu} / \mathrm{ml}$ ) was produced in the packaging cell line HEK 293, as previously described (Laplagne et al., 2006). Viral solutions were injected in the brain of young $5 \mathrm{HT}_{3}$-EGFP pups to label newborn cells. The generation of the $5 \mathrm{HT}_{3}$-EGFP transgenic mice and the correct expression of the transgene have been described previously (Inta et al., 2008). Injections were performed as follows: $1 \mu \mathrm{l}$ of viral solution was injected through glass micropipettes into the SVZ of 4 -d-old $5 \mathrm{HT}_{3}$-EGFP mice using the following coordinates from bregma: $0.6 \mathrm{~mm}$ anterior, $1.2 \mathrm{~mm}$ lateral, 1.5 $\mathrm{mm}$ ventral. Pups were returned to their mothers and killed after $2 \mathrm{~d}$ to 10 weeks. In some experiments, a retroviral vector expressing GFP instead of RFP was injected in wild-type pups, following the same procedure.

For transsynaptic tracing studies, we used a construct that was used previously in transgenic mice to label the presynaptic neuron with GFP and postsynaptic neurons with a fusion of a C-terminally truncated wheat germ agglutinin (tWGA) and DsRed (Sugita and Shiba, 2005). The sequence coding for GFP-IRES-tWGA/DsRed was subcloned from a plasmid kindly provided by Dr. M. Sugita (Hiroshima University, Hiroshima, Japan) to a retroviral backbone vector containing the RSV promoter. Retrovirus production, purification and injections in the SVZ of P4 pups were as described above. Mice were killed after 21 or $40 \mathrm{~d}$ postinjection.

For lentiviral injections, we used a replication-deficient lentiviral vector expressing copGFP (viral plasmid CDH-EF1-copGFP, SBI) or a lentiviral vector expressing ChR2-YFP under the control of the synapsin promoter (Zhang et al., 2007) that were produced and injected into the brain as previously described (Khodosevich et al., 2009). Briefly, $1 \mu \mathrm{l}$ of high titer $\left(\sim 5.10^{8} \mathrm{cfu} / \mathrm{ml}\right)$ recombinant lentivirus was injected into lateral ventricles of P4 wild-type mice to infect the whole SVZ. Mice were killed 3-6 weeks later. All procedures were approved by the local animal care committee.

In utero retrovirus labeling of newborn neurons in the embryonic brain. Staged pregnant $5 \mathrm{HT}_{3}$-EGFP females were anesthetized using continuous exposure to isoflurane and the abdominal cavity was cut open. Retroviral-CAG-RFP solution $(1.5 \mu \mathrm{l})$ was injected through the uterine wall into the lateral ventricle of the embryonic telencephalon. The embryos were then allowed to develop in utero until birth.

Embryonic tissue dissection, cell dissociation, and transplantation into the postnatal brain. The caudal ganglionic eminence was dissected from 5HT3-EGFP embryos, aged embryonic day 14.5 (E14.5), in sterile PBS-sucrose solution. Tissue explants were mechanically dissociated by gently pipetting through a $200 \mu$ l plastic tip (10-15 times) and kept on ice until transplantation. Cells to be grafted were front-loaded in glass micropipettes prefilled with mineral oil. GFP-positive cells were injected into cortical layer VI of 4 -d-old C57BL/6 mice using the following coordinates from bregma: $1 \mathrm{~mm}$ anterior, $1 \mathrm{~mm}$ lateral, 0.8 mm ventral.

Slice preparation and electrophysiology. Parasagittal brain sections (250-300 $\mu \mathrm{m}$ thick) were prepared from transgenic mice or transplanted wild-type mice (P2-P78) using a vibratome (HR2, Sigmann Elektronik). Whole-cell voltage and current-clamp recordings were made at room temperature $\left(22-24^{\circ} \mathrm{C}\right)$ from visually identified, EGFP/RFP-positive neurons or EGFP-positive neurons using an EPC8 amplifier (HEKA) and an upright microscope (BX51, Olympus or DM6000, Leica) equipped with IR-differential interference contrast and standard epifluorescence. To patch prenatally born multipolar and bipolar cells, and postnatally born multipolar cells, patch pipettes had a resistance of 5-6 M $\Omega$. To patch postnatally generated neuroblast migrating in the RMS, corpus callosum and cortex, and small axonless cells in cortical layer VI, patch pipettes had a resistance of $8-10 \mathrm{M} \Omega$. Patch pipettes were filled with the following (in mM): $127.5 \mathrm{KCl}, 11 \mathrm{EGTA}, 1 \mathrm{CaCl}_{2}, 2 \mathrm{MgCl}_{2}, 10 \mathrm{HEPES}, 2$ Mg-ATP, titrated to pH 7.4 with $35 \mathrm{~mm} \mathrm{KOH}$ (final osmolarity 290 mOsm). Biocytin $(2.5 \mathrm{mg} / \mathrm{ml})$ was routinely added to the solution. Morphological reconstructions were performed using Neurolucida, and Neuroexplorer (MBF Bioscience).

Slices were continuously superfused with ACSF containing the following (in mM): $120 \mathrm{NaCl}, 3.5 \mathrm{KCl}, 2.5 \mathrm{CaCl}_{2}, 1.3 \mathrm{MgSO}_{4}, 1.25 \mathrm{NaH}_{2} \mathrm{PO}_{4}, 25$ $\mathrm{NaHCO}_{3}, 25$ glucose. Cells were voltage-clamped at $-60 \mathrm{mV}$ unless otherwise indicated. Junction potential $(-4.9 \mathrm{mV})$ was not corrected. Signals were filtered at $3 \mathrm{kHz}$, sampled at $10 \mathrm{kHz}$ and converted into Axon binary files using ABF utility (Synaptosoft). Off-line analysis was performed with Clampfit 10 (Molecular Devices). For photostimulation we used a laser delivering blue light ( $473 \mathrm{~nm}$; CrystaLaser) through an optic fiber positioned just above the recorded neurons.

The decay phase of the EPSCs was fitted with a monoexponential $[A \exp (-t / \tau)]$, using a nonlinear Chebyshev fitting. The decay phase of the IPSCs was fitted with the sum of two exponentials $[A \exp (-t / \tau 1)+$ $B \exp (-t / \tau 2)]$; IPSC time constants are reported as an amplitudeweighted mean $\tau_{\mathrm{w}}=(A \tau 1+B \tau 2) /(A+B)$.

The unpaired, two-tailed Student's $t$ test was used to compare variables between groups. Data are shown as mean \pm SEM, and a $p$-value $<0.05$ was considered statistically significant.

Imaging. Imaging of fluorescent labeled cells in acute slices was performed on a TCS SP5 microscope (Leica) equipped with a $20 \times(1$ numerical aperture) water-immersion objective. A picosecond laser (Mai-Tai, Spectra Physics) or an Argon laser were used to excite GFP at $900 \mathrm{~nm}$ (two-photon imaging) or $488 \mathrm{~nm}$ (confocal imaging), respectively. A He-Ne laser was used to excite RFP and sulforhodamine B at 543 $\mathrm{nm}$. Images $(512 \times 512$ pixels) were acquired at $0.15-0.25 \mu \mathrm{m}$ (single cell imaging) or $1.5 \mu \mathrm{m}$ (field imaging) per pixel resolution in the $x y$ dimension and $0.25-2 \mu \mathrm{m}$ steps in the $z$ dimension. Some morphological reconstructions of small axonless neurons and immature neuroblasts in the RMS were performed from the complete 3D image stacks using Neurolucida (MBF Bioscience) after adjusting for contrast and brightness in ImageJ (MacBiophotonics-NIH). Movies were made from 3D stacks acquired sequentially every $15-20 \mathrm{~min}$. Maximal intensity projections were subsequently aligned in ImageJ (MacBiophotonics-NIH).

Immunohistochemistry. Mice were intracardially perfused with $4 \%$ PFA in PBS and the brains were removed and fixed overnight in 4\% PFA. Brain slices $(60 \mu \mathrm{m})$ were cut using a vibratome. Free-floating sections were first permeabilized in $0.2 \%$ Triton X-100 in PBS for $30 \mathrm{~min}$ and blocked in 3\% BSA in PBS for $1 \mathrm{~h}$ before incubation with the primary antibody at $4^{\circ} \mathrm{C}$ overnight (the permeabilization step was omitted for the anti-GAD65/67). After three washes in PBS, the sections were incubated with the secondary antibody for $2 \mathrm{~h}$ at room temperature, washed three times with PBS and mounted. For nuclear staining, sections were incubated for $5 \mathrm{~min}$ at room temperature after the last antibody washing with DAPI (300 nM, Invitrogen), washed again and mounted. For 5-bromo2 '-deoxyuridine (BrdU) stainings, sections were incubated in $\mathrm{HCl}(1 \mathrm{M})$ at $45^{\circ} \mathrm{C}$ during $45 \mathrm{~min}$ followed by $15 \mathrm{~min}$ in Tris, $\mathrm{pH} 8.5$ (10 mM) at room temperature before BrdU antibody incubation. Primary antibodies were as follows: rabbit anti-EGFP (1:10,000, Invitrogen), chicken antiEGFP (1:1000, Abcam), mouse anti-calretinin (CR) (1:5000, Swant), mouse anti-MAP2 (1:1000, Sigma) rabbit anti-VGAT (1:250, Millipore), 
Table 1. List of the different odoriferous items used to enrich the olfactory environment

\begin{tabular}{llll}
\hline Day 01 (P7) & Chocolate & Coffee & Gums \\
Day 02 (P8) & Curry & Cinnamon & Fruit tea \\
Day 03 (P9) & Thyme & Black pepper & Lemon \\
Day 04 (P10) & Oregano & Honey & Orange \\
Day 05 (P11) & Vinegar & Banana & Dill \\
Day 06 (P12) & Paprika & Strawberry & Rosemary \\
Day 07 (P13) & Nutmeg & Garlic & Vanilla \\
Day 08 (P14) & Peppermint & Onion & Carrots \\
Day 09 (P15) & Cheese & Cumin & Leeks \\
Day 10 (P16) & Mango & Anise & Almond tea \\
Day 11 (P17) & Pineapple & Peach tea & Lavender \\
Day 12 (P18) & Pear & Tarragon & Chamomile \\
Day 13 (P19) & Melon & Mushroom & Whole cloves \\
Day 14 (P20) & Sage & Coconut & Raspberry \\
Day 15 (P21) & Olive & Kiwi & Avocado \\
Day 16 (P22) & Peanuts & Mandarin & Laurel leaves \\
Day 17 (P23) & Salmon & Apple & Sesame oil \\
Day 18 (P24) & Lime & Marjoram & Papaya \\
Day 19 (P25) & Grapes & Celery & Peppers \\
Day 20 (P26) & Pistachios & Mix: Fennel, Celery & Green asparagus \\
Day 21 (P27) & Sunflower seeds & Ketchup & Earl Grey tea \\
Day 22 (P28) & Olive oil & Mint chewing gum & Parsley \\
\hline & & & \\
\hline
\end{tabular}

mouse anti-synaptophysin (1:250, Millipore), rat anti-BrdU (1:500, Accurate Chemical), rabbit anti-DsRed (1:1000, Living Colors, Clontech), rabbit anti-Tbr1 (1:1000, Abcam), rabbit anti-GAD65/67 (1:1000, Millipore).

Secondary antibodies were as follows: anti-rabbit Alexa Fluor 488 (1: 1.000, Invitrogen), anti-chicken Alexa Fluor 488 (1:1.000, Invitrogen), anti-mouse Cy3 (1:1.000, Jackson ImmunoResearch Laboratories), antirabbit Cy3 (1:1.000, Jackson ImmunoResearch Laboratories), anti-rat Cy3 (1:1.000, Jackson ImmunoResearch Laboratories). Sections were analyzed on a confocal microscope Zeiss LSM510.

Birth-dating analysis. Pregnant mice were injected intraperitoneally with $50 \mathrm{mg} / \mathrm{kg} \mathrm{BrdU}$ (Sigma) (body weight) five times every $2 \mathrm{~h}$ at E16.5, E18.5 following a protocol described previously (Xu et al., 2004). For postnatal neurogenesis, the same regime at $20 \mathrm{mg} / \mathrm{kg}$ was used at P1, P7, $\mathrm{P} 15$, and P30. Animals were killed after $28 \mathrm{~d}$. To determine the number of EGFP/BrdU-positive cells, every sixth section of $50 \mu \mathrm{m}$ (300 $\mu \mathrm{m}$ intervals) of one cerebral hemisphere from each animal was processed for immunohistochemistry as described before. EGFP/BrdU-positive cells were counted using a Zeiss LSM510 confocal microscope with a $63 \times$ oil-immersion objective. Colocalizing cells were identified and counted by confocal $\mathrm{Z}$ sectioning within two $63 \times$ magnification optical fields for each region in the deep layers of orbital and olfactory cortex.

Electron microscopy. For visualization of anti-GFP primary antibodies, slices were incubated either in biotinylated anti-rabbit antibody, followed by $\mathrm{ABC}$ and $\mathrm{DAB}$ or in goat anti-rabbit IgG ultra small immunogold reagent (Aurion Ultra Small Immunogold Reagent) diluted 1:100 in incubation solution (0.1\% Aurion BSA-c, 15 mm NaN3 in PBS, pH 7.4) for $1 \mathrm{~h}$. The ultra small gold particles were gold-enhanced by GoldEnhance EM as described by the manufacturer (Nanoprobes). In both cases, antibody labeling was followed by osmification and Epon resin flat embedding. Serial $60-90 \mathrm{~nm}$ sections were cut and contrasted with lead citrate. The electron micrographs were taken on an EM 10 Zeiss CR electron microscope.

Odor enrichment. C57BL/6J mice were kept in standard laboratory cages. They were randomly assigned to two experimental groups. The group exposed to the olfactory enriched environment $(n=6)$ consisted of mice that were exposed for $21 \mathrm{~d}$ (from P8 until P29) to common odoriferous items (Table 1). Three new odors were presented daily in tea balls that were left in the cage for $24 \mathrm{~h}$. Mice in the control group $(n=8)$ were reared under the same conditions except that the tea balls were left empty. Tea balls were exchanged daily also for the control group. Mice had access to food and tap water ad libitum and were kept on a $12 \mathrm{~h}$ light/dark cycle, with constant temperature. The animals were kept with their mothers until P22, separated according to their gender after weaning and killed on the last treatment day. To determine the quantity of newly generated cells, BrdU was administered intraperitoneally (30 $\mathrm{mg} / \mathrm{kg}$ body weight) at days 2, 3, 4 and 5 after birth. At P29, the mice were deeply anesthetized with a mixture of xylazine and ketamine and perfused transcardially with $4 \%$ paraformaldehyde in phosphate buffer (PBS). Double immunostainings for BrdU and calretinin allowed the identification of $\mathrm{BrdU}^{+} \mathrm{CR}^{+}$unipolar small axonless neurons. We used confocal microscopy to count the number of $\mathrm{CR}^{+} \mathrm{BrdU}^{+}$unipolar cells present in the olfactory and orbital cortex from controls and mice kept in an enriched environment. Only sagittal sections containing the entire RMS (7 sections per hemisphere) were used for analysis. The results are given as mean \pm SEM. Two-tailed Student's $t$ test was used to compare variables between groups.

\section{Results}

\section{Two types of postnatally generated neurons}

We stereotaxically injected a replication-defective retrovirus into the $\mathrm{SVZ}$ of $5 \mathrm{HT}_{3}$-EGFP mouse pups at $\mathrm{P} 4$ to express the fluorescent protein RFP in dividing, newborn cells (Fig. $1 A, B$ ). We have shown previously, using BrdU injections in newborn pups, that postnatally born $\mathrm{EGFP}^{+}$cells in these mice do not express glial markers (Inta et al., 2008). Most cells labeled with EGFP and RFP $\left(\mathrm{EGFP}^{+} \mathrm{RFP}^{+}\right.$cells) eventually migrated to the olfactory bulb. However, a substantial proportion of these cells migrated to the cortex.

We could divide $\mathrm{EGFP}^{+} \mathrm{RFP}^{+}$cells en route to the cortex into five stages of development according to their location, morphology and physiological properties. The first two stages were characterized by their location: stage 1 cells were neuroblasts in tangential migration in the rostral migratory stream while stage 2 cells had detached from the RMS and migrated radially toward the cortex through the corpus callosum or the lower cortical layers (Fig. 1C,D).

In the last three stages (stage 3 to stage 5), cells reached their final destination in the cortex. Two clearly distinct neuronal subtypes could be distinguished from that point onward: small axonless neurons located preferentially in deeper cortical layers, and larger multipolar neurons in layers II-VI. In each of these two subtypes, cells were classified based on their electrophysiological properties: stage 3 cells received GABAergic spontaneous activity; stage 4 cells showed, in addition, glutamatergic spontaneous activity; stage 5 cells had acquired their final, mature spiking pattern in response to prolonged depolarizations, either a single action potential in small axonless neurons or a regular train of action potentials in multipolar neurons (Fig. $1 E$ ).

\section{Properties of migrating cells (stages 1 and 2)}

Two to $6 \mathrm{~d}$ after retrovirus infection, we patch-clamped stage 1 $\mathrm{EGFP}^{+} \mathrm{RFP}^{+}$cells in the rostral migratory stream $(n=14,8$ mice). At that stage, cells en route to the cortex could not be distinguished from cells migrating to the olfactory bulb. They exhibited morphological features of migrating cells, with one or several short processes and a small cell body (Fig. $2 A$ ). Most of these cells ( 8 of 14) did not spike in response to a depolarizing step (Fig. $2 B$ ), although in six cells we detected a small sodium spike that was blocked by TTX $(1 \mu \mathrm{M})(n=2$, data not shown). None of them exhibited spontaneous synaptic activity (Fig. 2C; $n=14)$. In voltage clamp, they showed a weak delayed rectifier $\left(I_{\mathrm{K}(\mathrm{V})}\right)$ potassium current that was blocked by TEA (tetraethylammonium) (3 mM) and a small sodium current blocked by TTX $(1 \mu \mathrm{M})$ (Fig. $2 D ; n=9)$. In all cells $(n=9)$, pressure-applying GABA $(100 \mu \mathrm{M})$ in voltage clamp resulted in inward currents blocked by bicuculline $(20 \mu \mathrm{M})$, indicating the presence of extra- 

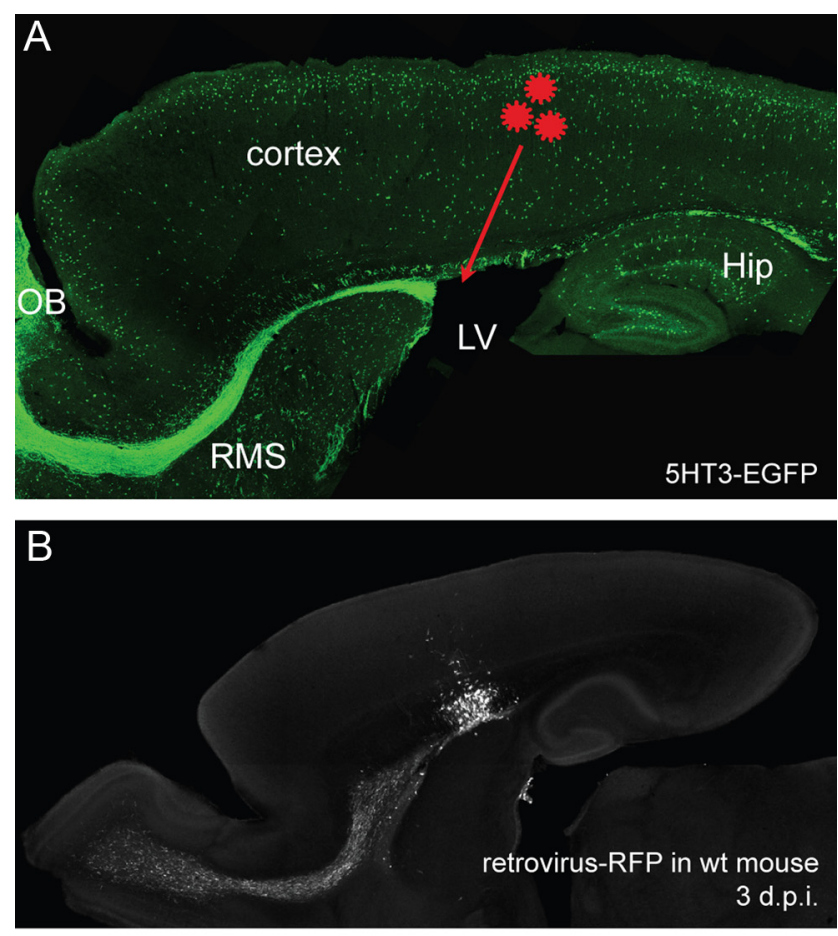

C
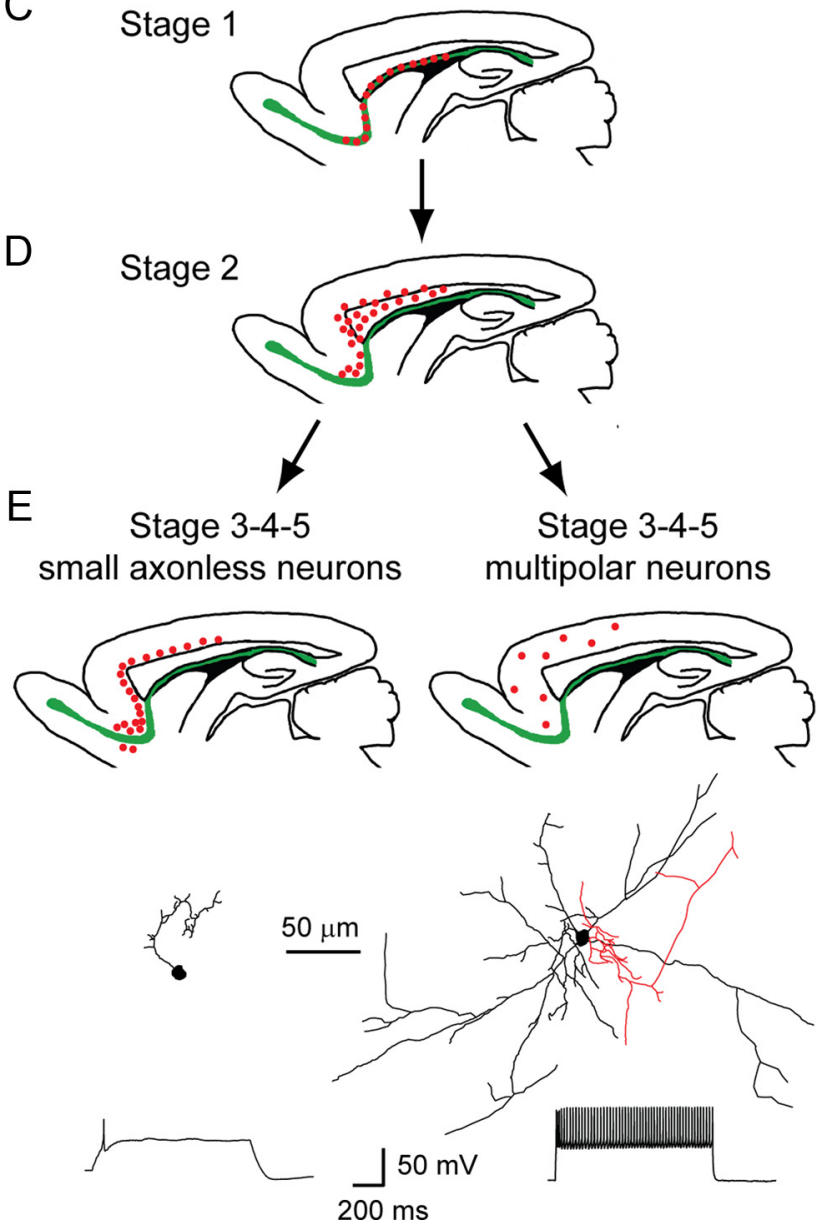

Figure 1. Combinatorial approach to study and classify postnatally generated cortical interneurons. $\boldsymbol{A}$, Postnatally born cells originating in the SVZ were identified and staged in $5 \mathrm{HT}_{3}$ EGFP mice that were injected with a retroviral vector (red stars) expressing RFP in newborn cells. $\boldsymbol{B}$, Control injection of the retrovirus-RFP in a P4 wt mouse showing that $3 \mathrm{~d}$ after injection fluorescence is confined to the injection area, the SVZand the RMS. $\boldsymbol{C}-\boldsymbol{E}$, Based on their location, synaptic $\mathrm{GABA}_{\mathrm{A}}$ receptors. In the same cells, application of glutamate $(200 \mu \mathrm{M})$ at a holding potential of $-60 \mathrm{mV}$ evoked a current in two cells out of 10, that could be blocked by CNQX 50 $\mu \mathrm{M}$. Coapplication of NMDA $(200 \mu \mathrm{M})$ and glycine $(50 \mu \mathrm{M})$ at $+40 \mathrm{mV}$ failed to elicit a current in all cells except one, in which it was inhibited by APV $100 \mu \mathrm{M}$ (Fig. 2E,F). This suggests that AMPA/kainate receptors and NMDA receptors are expressed at low levels at this stage.

Three to $13 \mathrm{~d}$ post-retroviral injection (3-13 d.p.i.), stage 2 $\mathrm{EGFP}^{+} \mathrm{RFP}^{+}$cells with a migratory appearance were found in the corpus callosum and lower layers of the cortex $(n=12,7$ mice). These cells had one or two long processes that rarely ramified into smaller branches, stemming from a small, rounded, or occasionally elongated, cell body (Fig. 2 A). Unlike stage 1 neuroblasts in the RMS, most stage 2 cells exhibited a small sodium spike (Fig. $2 \mathrm{~B} ; 10$ of 12 cells). No spontaneous postsynaptic current could be recorded from these cells in voltage clamp (Fig. 2C). Using time-lapse confocal microscopy in acute brain slices from $5 \mathrm{HT}_{3}$-EGFP mice aged P7-P12, we could follow the migration of $\mathrm{EGFP}^{+}$cells through the corpus callosum and lower cortical layers for 4-16 h, and subsequently obtained whole-cell recordings from $\mathrm{EGFP}^{+}$cells identified as migrating cells. Most of neuroblasts at this stage had an unbranched leading process and showed a growth cone-like structure at the tip. The outgrowth of a leading process always preceded somal translocation. All recorded migratory cells ( $n=8,8$ mice) had features of stage 2 cells, including typical migrating morphology and lack of synaptic activity (data not shown). This further designates stage 2 cells as migrating cells. Depolarizing stage 2 cells in voltage clamp induced inward sodium currents and outward potassium currents that were larger than in stage 1 cells $(n=11$; Fig. $2 D)$. Pressureapplying GABA $(100 \mu \mathrm{M})$ in voltage clamp elicited inward currents blocked by the $\mathrm{GABA}_{\mathrm{A}}$ receptor antagonist bicuculline (20 $\mu \mathrm{M}$ ) in all stage 2 cells that were tested (Fig. $2 E ; n=9$ ). Pressureapplying glutamate $(200 \mu \mathrm{M})$ onto these cells at a holding potential of $-60 \mathrm{mV}$ often resulted in an inward current ( 12 of 16 cells tested) blocked by CNQX (50 $\mu \mathrm{M})$. In most cells (14 of 17), coapplying NMDA $(200 \mu \mathrm{M})$ and glycine $(50 \mu \mathrm{M})$ at $+40 \mathrm{mV}$ induced an outward current antagonized by APV $(100 \mu \mathrm{M})$ (Fig. $2 F$ ). These results indicate that the majority of cells, once detached from the RMS and in radial migration toward the cortex or within the cortex, express extrasynaptic AMPA/kainate and NMDA receptors.

Postnatally generated small axonless neurons (stages 3-5)

Most cells stopped their migration in layer VI of the cortex. They had a single, main apical process that branched into smaller processes (Fig. 3A). These cells exhibited spontaneous PSCs when held at $-60 \mathrm{mV}$ (Fig. $3 \mathrm{~B}, \mathrm{C}$ ). A high intracellular $\left[\mathrm{Cl}^{-}\right]$solution was used to increase the driving force for chloride-mediated IPSCs. Thus, under these recording conditions, IPSCs and EPSCs both triggered inward currents at $-60 \mathrm{mV}$. IPSCs and EPSCs could easily be distinguished on the basis of amplitude, kinetics, and pharmacological characteristics. Stage 3 cells were found from 9 to $15 \mathrm{~d}$ after retrovirus injection $(n=7,7$ mice), and

$\leftarrow$

morphology and firing pattern, postnatally generated neurons (red dots) were classified into five stages, and from stage 3 onwards could be divided in two categories, small axonless neurons ( $\boldsymbol{E}$, left panels) and multipolar neurons ( $\boldsymbol{E}$, right panels). Two representative examples of each cell type at stage 5 (axon in red, dendrites in black) and their typical firing pattern in response to a $1 \mathrm{~s}$ depolarizing step in current-clamp are presented at the bottom. OB, Olfactory bulb; LV, lateral ventricle; Hip, hippocampus. 
A

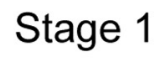

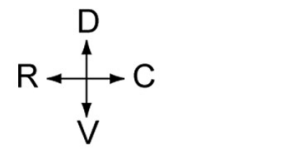

$\overline{\mathrm{RMS}}$

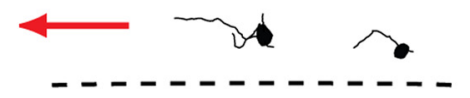

B

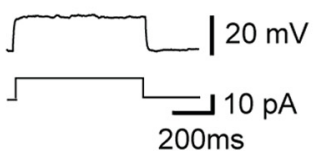

C
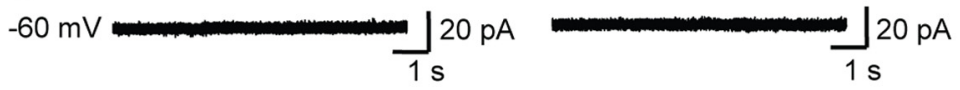

D

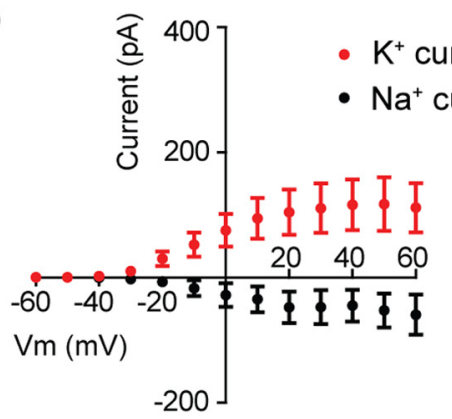

E

$-60 \mathrm{mV}$

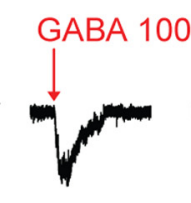

F
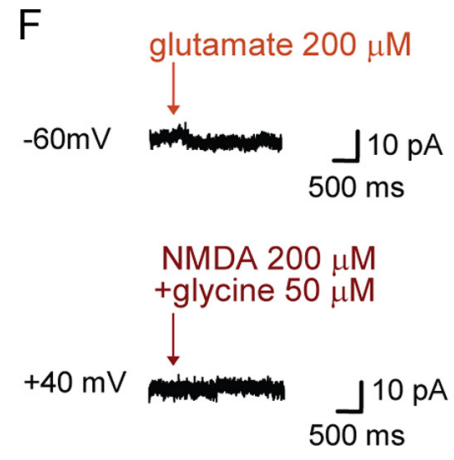

Stage 2
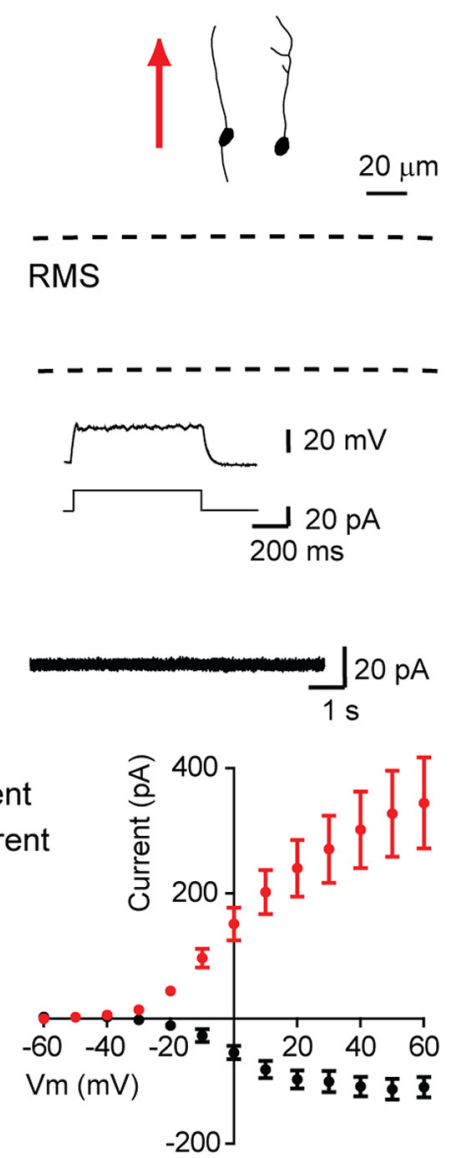

$-200$
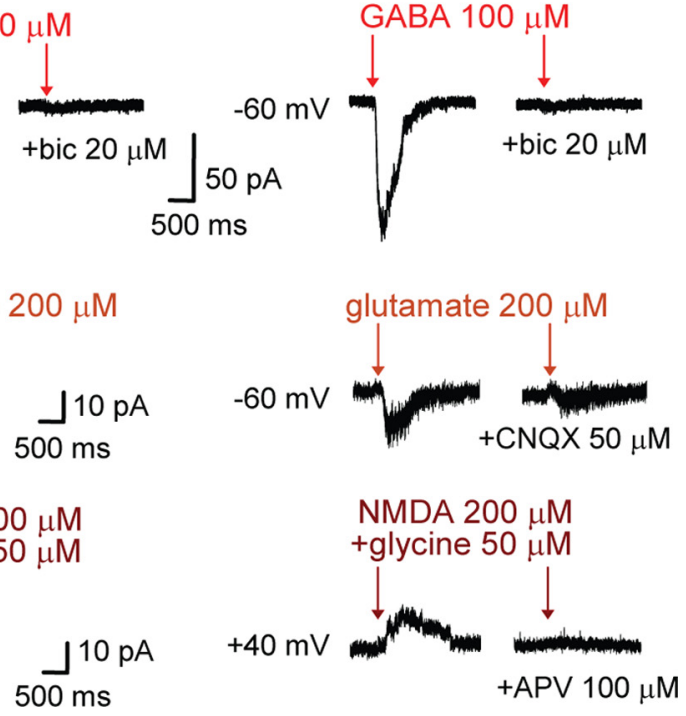

Figure 2. Functional characteristics of stage $1-2$ migrating cells. $\boldsymbol{A}$, Morphological reconstructions of EGFP ${ }^{+}$RFP $^{+}$cells migrating tangentially in the RMS (stage 1, left) or radially through the corpus callosum (stage 2, right). Red arrows indicate the direction of migration. R, C, D, and V refer to the rostro-caudal and dorso-ventral axis, respectively. $\boldsymbol{B}$, Responses (top traces) to depolarizing steps (bottom traces) in current-clamp in stage 1 and 2 cells. $C$, Recordings obtained in voltage clamp at $V_{\text {hold }}=-60$ $\mathrm{mV}$ showing the absence of spontaneous activity in stage 1 and 2 cells. $\boldsymbol{D}, I-V$ curves showing $\mathrm{Na}^{+}$and $\mathrm{K}^{+}$currents evoked by depolarizing voltage steps (increments of $10 \mathrm{mV}$ ) in stage 1 and 2 cells. Each data point was calculated by subtracting currents before and after $1 \mu \mathrm{m}$ TTX application ( $\mathrm{Na}^{+}$currents) or before and after $3 \mathrm{~mm}$ TEA application ( $\mathrm{K}^{+}$currents). E, GABA $(100 \mu \mathrm{M})$ elicited inward currents blocked by bicuculline $(20 \mu \mathrm{m})$ in stage 1 (left) and stage 2 (right) cells recorded in voltage clamp $\left(V_{\text {hold }}=\right.$ $-60 \mathrm{mV}$ ). $\boldsymbol{F}$, AMPA and NMDA receptor-mediated currents in stage 2 but not stage 1 cells. AMPA responses were recorded at $V_{\text {hold }}=-60 \mathrm{mV}$, induced by pressure applications of glutamate $(200 \mu \mathrm{M})$, and blocked by CNQX $(50 \mu \mathrm{M})$, while NMDA responses were recorded at $+40 \mathrm{mV}$, induced by pressure application of NMDA $(200 \mu \mathrm{M})$ plus glycine $(50 \mu \mathrm{M})$, and blocked by APV $(100 \mu \mathrm{M})$.

received only infrequent IPSCs that could be blocked by bicuculline $(20 \mu \mathrm{M})$. Stage 4 cells, detectable from $12 \mathrm{~d}$ onwards after virus infection $(n=20,15$ mice), were similar to stage 3 cells, but exhibited in addition spontaneous glutamatergic EPSCs that were blocked by the AMPA/kainate receptor inhibitor CNQX $(20 \mu \mathrm{M})$. To test whether synaptic activity could be detected earlier by raising the probability of neurotransmitter release, we increased the ACSF temperature to $32-33^{\circ} \mathrm{C}$. Under these conditions, spontaneous IPSCs were observed in one cell at 8 d.p.i. ( 6 cells examined in 3 mice, at $6-8$ d.p.i.), but EPSCs were not found earlier than 12 d.p.i. ( 9 cells examined in 5 mice, at $9-11$ d.p.i.; data not shown). In stage 3 and 4 cells, injection of depolarizing current in currentclamp induced a sodium spike, with an amplitude always smaller than $12 \mathrm{mV}$ (Fig. $3 D$, left). Finally, stage 5 neurons were characterized by the firing of a single action potential (amplitude $31.4 \pm 2.6 \mathrm{mV}$, $n=15,11$ mice; Fig. $3 D$ ) and were first found $18 \mathrm{~d}$ after retrovirus-RFP injection. We recorded from these neurons as late as $74 \mathrm{~d}$ postinjection, indicating that they survive in the adult brain. Even at that age, they never responded to prolonged depolarization with more than a single action potential. Importantly, stage 5 neurons kept a small, unipolar morphology and were deprived of axon. Immunostainings of unipolar $5 \mathrm{HT}_{3}$-EGFP cells with antibodies to the dendritic protein MAP2 labeled their only process (Fig. 4A). These findings were further confirmed at the EM level. The single process emanating from the cell body showed typical dendritic organelles such as microtubules, elongated mitochondria and agranular endoplasmic reticulum, which confirmed its dendritic nature (Fig. $4 B$ ). In summary, our results show that cells generated postnatally in the SVZ migrate to the cortex where they acquire neuronal physiological properties. Their morphological and physiological characteristics make them unique among cortical interneurons. To our knowledge, these neurons have not yet been described in the cortex, presumably because of their atypical features and location in lesser-studied cortical regions (see below, Distribution of small axonless cells in the cortex). To emphasize their distinct morphological appearance, we called them "small axonless neurons."

\section{Postnatally generated multipolar cells (stages 3-5)}

In addition to small cortical interneurons with the aforementioned characteristics, 
SMALL AXONLESS NEURONS

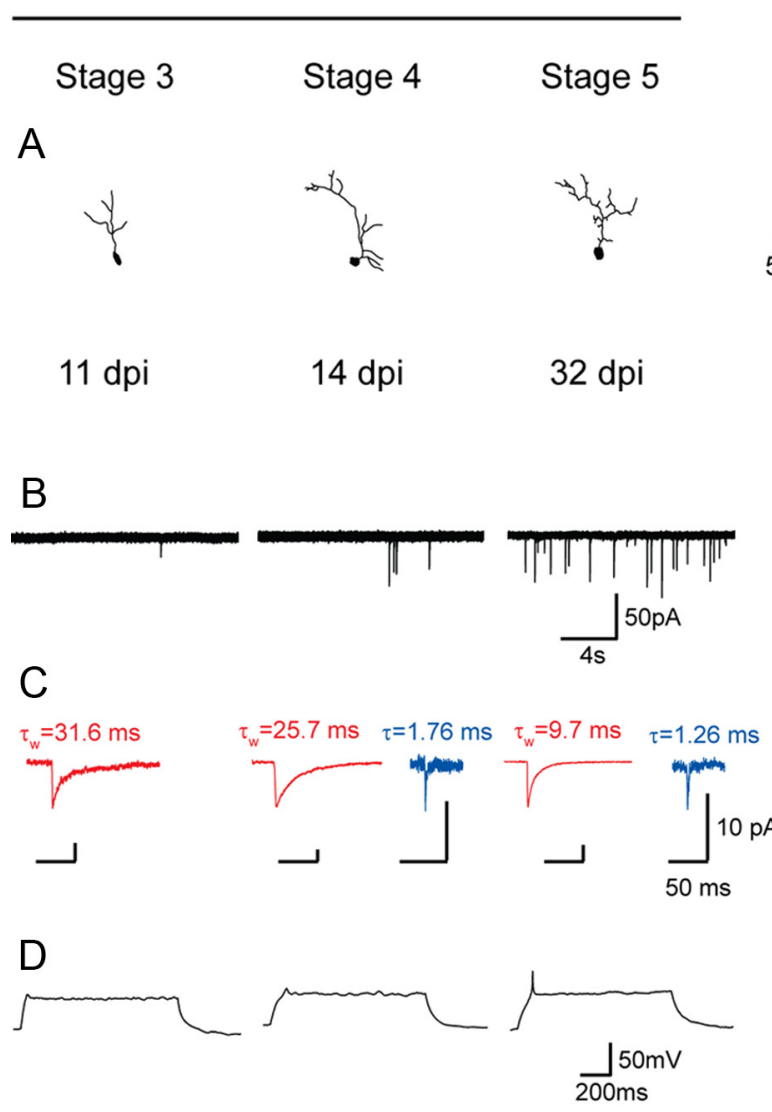

MULTIPOLAR NEURONS

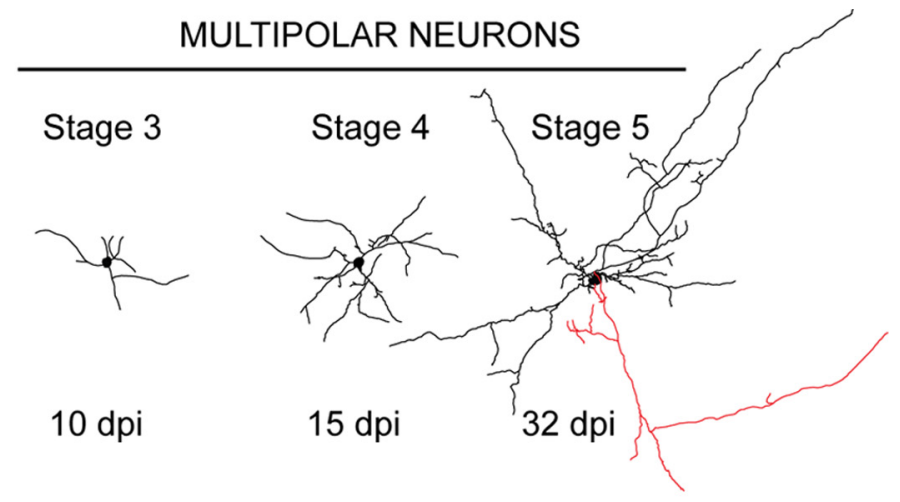

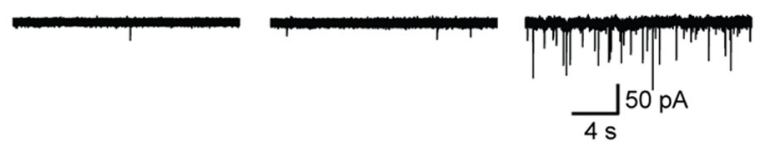
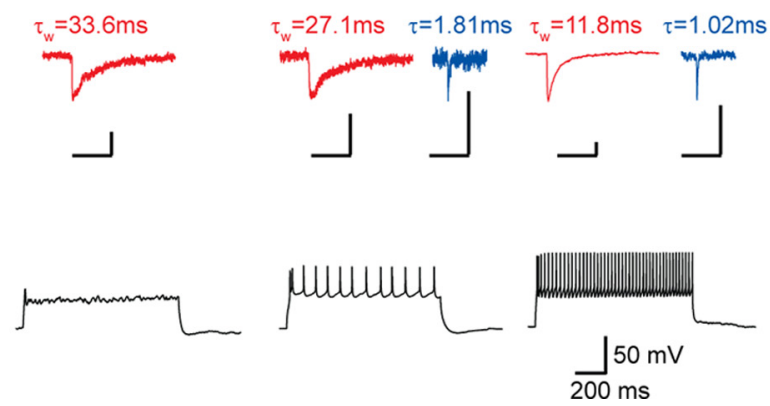

Figure 3. Morphological and electrophysiological features in stage 3-5 small axonless versus multipolar neurons. $A$, Morphological reconstructions of postnatally generated small axonless neurons and multipolar neurons at the indicated stages. $\boldsymbol{B}$, Representative voltage-clamp recordings from the neurons shown in $\boldsymbol{A}$ demonstrating the development of spontaneous activity in stage 3-5 cells. C, In both cell classes at stage 3, only GABAergic PSCs (red traces) could be recorded. From stage 4 onwards, glutamatergic PSCs (blue traces) were also present. Small axonless neurons, red traces: mean of 5 (stage 3), 10 (stage 4) and 68 (stage 5) GABAergic PSCs; blue traces: mean of 9 (stage 4) and 14 (stage 5) glutamatergic PSCs. Multipolar neurons, red traces: mean of 5, 10 and 43 GABAergic PSCs; blue traces: mean of 9 and 34 glutamatergic PSCs. Decay times are indicated above each trace. $\boldsymbol{D}$. Current-clamp recordings show the gradual increase in spiking activity in response to $1 \mathrm{~s}$ depolarizing steps. Note that small axonless neurons never fire more than a single action potential in response to a sustained depolarization, even at their most advanced stage of maturation.

we also recorded from $21 \mathrm{EGFP}^{+} \mathrm{RFP}^{+}$multipolar cells with distinct electrophysiological properties. These cells were distributed in cortical layers II-VI (Fig. 1E). They had a larger soma than small axonless cells, were multipolar and possessed an axon (Figs. 1E, 3A). These cells first showed spontaneous IPSCs $10 \mathrm{~d}$ after virus injection (stage 3 ). At the same age depolarizing current injections already elicited a small action potential, $8 \mathrm{~d}$ earlier than in small axonless cells (Fig. $3 B-D$, right traces). From $13 \mathrm{~d}$ after viral injections onward, multipolar cells generated at $\mathrm{P} 4$ had spontaneous EPSCs in addition to IPSCs, and fired more than one AP in response to sustained depolarizations (stage 4). In mature multipolar neurons, prolonged depolarizing current injection generated trains of action potentials at constant frequency after a slight accommodation (Fig. 3D; right traces, stage 5). This sustained firing pattern was first observed in one multipolar neuron $14 \mathrm{~d}$ after virus injection, and was present in most multipolar neurons aged at least $17 \mathrm{~d}$ ( 7 of 9). Postnatally born multipolar cells likely represent the tail end of embryonic neurogenesis of $5 \mathrm{HT}_{3}$-EGFP interneurons (see below, Maturation of embryonically generated neurons).

Intrinsic and synaptic properties in small axonless versus multipolar neurons

Neuroblasts migrating in the RMS and corpus callosum 3-7 d after viral infection had a very high input resistance $(5.96 \pm 0.87$
$\mathrm{G} \Omega ; n=19)$ and low cell capacitance $(9.27 \pm 1.81 \mathrm{pF} ; n=19)$, features that are typical of small immature cells expressing few ion channels on their cell membrane. Input resistance gradually decreased as postnatally generated cells matured, but remained high, reaching $4.02 \pm 0.25 \mathrm{G} \Omega$ in small axonless neurons aged $17 \mathrm{~d}$ or more $(n=25 ; p=0.001)$, reflecting their small somatic and dendritic size. Conversely, cell capacitance increased progressively over time but remained low, reaching $16.2 \pm 1.6 \mathrm{pF}$ for small axonless neurons recorded $17 \mathrm{~d}$ or more after retroviral infection $(n=25, p=0.006)$. Mature multipolar cells had significantly lower membrane resistance $(0.97 \pm 0.19 \mathrm{G} \Omega ; n=9)$ and higher cell capacitance $(42.9 \pm 4.9 \mathrm{pF} ; n=9)$ than small axonless neurons $(p<0.0001$ and $p<0.0001$, respectively; Fig. $5 A, B)$, although these parameters still classify them as high-input resistance, low-capacitance cortical neurons.

IPSC and EPSC frequencies increased as neurons developed (Fig. 5C,D). After $30 \mathrm{~d}$, spontaneous activity was significantly higher in multipolar neurons (IPSCs, $1.72 \pm 0.64 \mathrm{~Hz}$; EPSCs, $1.19 \pm 0.40 \mathrm{~Hz} ; n=6)$ than in small axonless neurons (0.41 \pm $0.11 \mathrm{~Hz}$ and $0.43 \pm 0.07 \mathrm{~Hz}$ respectively; $n=12 ; p=0.01$ and $p=$ 0.02 ), presumably because their longer dendrites can accommodate more synaptic connections with neighboring neurons. IPSC and EPSC amplitudes did not vary significantly during development (Fig. $5 E, F$ ). EPSC amplitudes, but not IPSC amplitudes, were higher in multipolar neurons than in small 

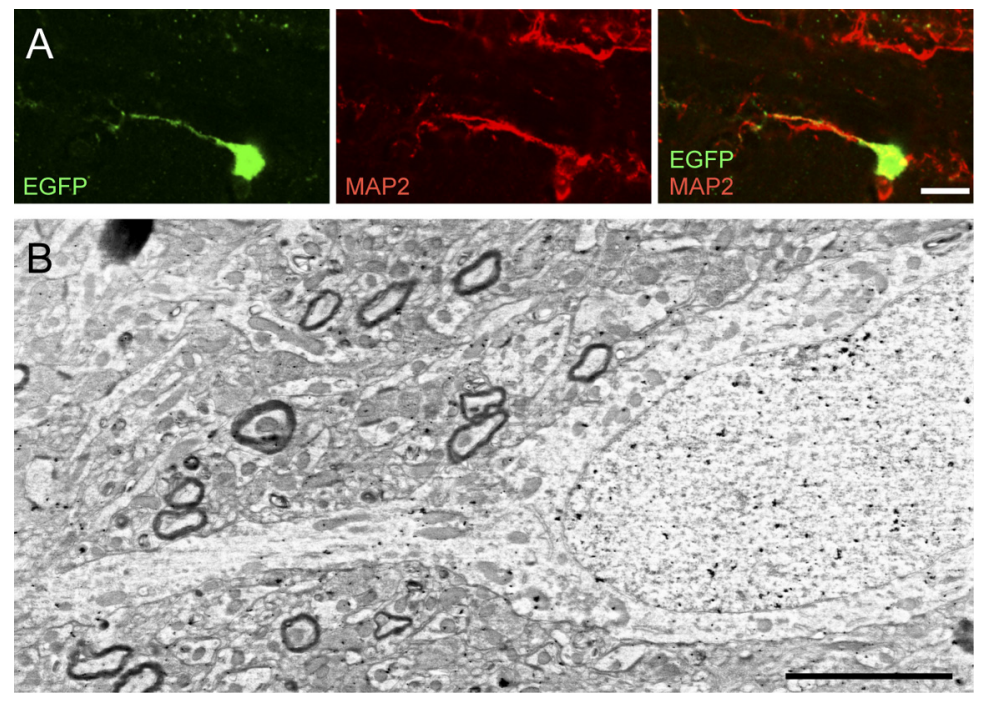

Figure 4. Dendritic nature of the single process of small axonless neurons. $A$, Double immunostaining for EGFP (in green) and the dendritic marker MAP2 (in red) of a 5HT - -EGFP small axonless neuron. Scale bar, $10 \mu \mathrm{m}$. $\boldsymbol{B}$, Electron micrograph showing a retrovirally infected small axonless neuron labeled with gold particles (black dots). The only neurite emanating from the cell body exhibits typical dendritic features (i.e., agranular endoplasmic reticulum, microtubules and elongated mitochondria). Scale bar, $1 \mu \mathrm{m}$.

axonless neurons $(10.32 \pm 1.46 \mathrm{pA}, n=13$ and $5 \pm 0.25 \mathrm{pA}$, $n=29$, respectively; $p<0.0001$ ), suggesting structural and/or molecular differences between glutamatergic synapses in the two neuronal types.

The decay time constant of IPSCs $\left(\tau_{\text {IPSC }}\right)$ markedly decreased with age in both cells types (Fig. $5 G, H$ ). This sharp decline of IPSC decay time during development has been observed in neocortical and hippocampal interneurons (Doischer et al., 2008; Okaty et al., 2009) and in cortical pyramidal cells in which it was attributed to the upregulation of $\alpha 1$ and $\alpha 4$ and downregulation of $\alpha 3$ and $\alpha 5 \mathrm{GABA}_{\mathrm{A}}$ receptor subunits (Dunning et al., 1999; Hutcheon et al., 2000; Bosman et al., 2002). Our results are consistent with the notion that this switch in receptor composition also takes place in neurons generated postnatally.

\section{Immunocytochemical markers in small axonless neurons}

We have previously shown that $83 \%$ of cortical cells born at $\mathrm{P} 4$ in the SVZ express CR and are mainly located in cortical layer VI. The other $17 \%$ reside in cortical layers II-VI and are CR-negative (Inta et al., 2008). To directly demonstrate that CR-expressing cells born at $\mathrm{P} 4$ detected immunocytochemically are identical to small axonless neurons studied here, we repeated the electrophysiological analysis in transgenic mice that express EGFP under the control of the CR promoter (Caputi et al., 2009). A retrovirus encoding RFP was injected in the SVZ of P4 CR-EGFP mice to label newly generated EGFP-positive, calretinin-expressing neurons. Using patch-clamp recordings in acute brain slices and morphological reconstructions, we show that P4generated EGFP-expressing neurons $\left(16 \mathrm{EGFP}^{+} \mathrm{RFP}^{+}\right.$neurons from 9 CR-EGFP mice) in the cortex of adult (P26-P46) CREGFP mice share the physiological and morphological features of small axonless neurons (Fig. 6A,D). Moreover, CR immunostaining experiments in wt mice confirmed that unipolar, CRpositive small axonless cells are found in cortical layer VI, in particular in the orbital and olfactory cortices, where they represent the majority of CR-positive cells in deeper layers. In contrast, CR-positive cells in the upper cortical layers are bipolar or multipolar (Fig. 6E,F).
To determine the layer-specific distribution of small axonless neurons, we used triple stainings for DAPI, CR, and EGFP in $60-\mu \mathrm{m}$-thick coronal sections from adult $5 \mathrm{TH}_{3}$-EGFP brains. Small axonless neurons could be readily identified based on their strong CR and EGFP labeling, unipolar morphology and small cell soma (diameter $7.31 \pm 0.23 \mu \mathrm{m}$ for $\mathrm{CR}^{+} \mathrm{EGFP}^{+}$ small axonless neurons, $n=15$ cells, versus $11.40 \pm 0.24$ for $\mathrm{CR}^{+} \mathrm{EGFP}^{+}$bipolar/multipolar cells, $n=15$ cells; $p<0.0001$ ). The binned distribution in cortical layers along the rostrocaudal axis showed that these cells populate mainly the deeper layers of the most rostral cortices (layer 3 of the olfactory cortex and layer 6 of the orbital cortex) (Fig. 6G).

$\mathrm{CR}$ is expressed in subpopulations of mature cortical GABAergic interneurons, but is also expressed transiently by immature glutamatergic cells. Therefore, we investigated whether small axonless neurons are GABAergic or glutamatergic. Tbr1 is a transcription factor expressed in early postmitotic glutamatergic neurons in the rostral migratory stream (Brill et al., 2009). We examined the presence of Tbrl in migrating neuroblasts in the RMS and corpus callosum of $5 \mathrm{TH}_{3}$ EGFP mice. Tbr1 staining was observed in the RMS and, occasionally, in the lower parts of the corpus callosum, but never colocalized with EGFP. On the contrary, GAD65/75 always colocalized with GFP in the same regions (data not shown). In the cortex of adult $5 \mathrm{TH}_{3}$-EGFP mice, unipolar $\mathrm{CR}^{+} \mathrm{GFP}^{+}$neurons were always positive for GAD65/67 but never for Tbr1 (Fig. $6 H, I)$. Additionally, GAD65/67 colocalized with GFP-positive, unipolar cells located in lower cortical layers 7 weeks after retrovirus-GFP injection in the neonatal SVZ of wt mice (Fig. $6 J$ ). Altogether, these results demonstrate that small axonless neurons are GABAergic and not glutamatergic.

Finally, we determined the proportion of small axonless neurons within the population of all $5 \mathrm{HT}_{3}$ receptor-expressing cortical neurons. We took recourse to $5 \mathrm{HT}_{3}$-EGFP mice and found that in the cortex, $\mathrm{CR}^{+}$small axonless cells represent $12.6 \pm 0.7 \%$ of all $5 \mathrm{HT}_{3}$-EGFP cells. Interestingly, there were substantial differences along the mediolateral axis. While in sagittal sections closer to the midline, small axonless neurons made up $22.2 \pm$ $1.2 \%$ of $5 \mathrm{HT}_{3}-\mathrm{EGFP}$ cortical neurons, this proportion was only $6.4 \pm 2.8 \%$ in more lateral ( $1.5 \mathrm{~mm}$ from the midline) sections of the cortex (14,399 cells in 2 animals; Table 2$)$.

\section{Distribution of small axonless neurons in the cortex}

To quantify the proportion of small axonless neurons born postnatally that migrate to the cortex, we injected a lentiviral vector expressing GFP in the SVZ of wt pups at P4. Using CR expression in postnatally born cortical cells as a proxy for small axonless neurons, we counted the number of $\mathrm{GFP}^{+} \mathrm{CR}^{+}$cells present in the cortex, and of $\mathrm{GFP}^{+}$cells in the olfactory bulb $21 \mathrm{~d}$ after lentiviral injection in infected mice. We found that cortical cells double-labeled with CR and GFP after lentiviral injection at P4 represent $1.4 \pm 0.4 \%$ of lentivirally transduced cells in the olfactory bulb ( 6 mice examined), an even slightly larger proportion than that of adult-generated periglomerular cells (Winner et al., 2002). 
We next examined the region-specific distribution of small axonless cells in more detail, using lentiviral vector-GFP injection in $\mathrm{P} 4$ wt pups. Twenty-one days after injection, we counted the number of cells immunolabeled for CR and GFP in fixed cortical tissue in six mice. We found that $65 \%$ of CR-positive cortical small axonless neurons migrate to the olfactory cortex (including $43 \%$ to the anterior olfactory cortex, $9 \%$ to the dorsal tenia tecta, $7 \%$ to the dorsal endopirifrom nucleus), $28 \%$ to the orbital cortex and the remaining $7 \%$ being distributed between the cingulate cortex, dorsal pedunculus, prelimbic cortex, infralimbic cortex and motor cortex (Fig. 7A-C).

\section{Developmentally regulated generation of small axonless neuron}

We examined the time course of small axonless neuron generation during mouse development. $5 \mathrm{HT}_{3}$-EGFP mice of different ages received five injections of BrdU to visualize newborn dividing cells and were killed 4 weeks after BrdU injection. Small axonless neurons were identified by EGFP expression, CR costaining and distinct unipolar morphology (Fig. 7D). We determined the proportion of $\mathrm{BrdU}^{+}$small axonless neurons in serial sections of the olfactory, orbital and motor cortices (Fig. $7 E$ ). Our results indicate that small axonless neurons are generated only after E16.5. Injections of BrdU at E18.5 yielded $3.5 \%$ of $\mathrm{BrdU}^{+}$small axonless neurons. Neurogenesis peaked at P1 $(9.5 \%$ of $\mathrm{BrdU}^{+}$small axonless neurons) and subsequently steadily decreased until adulthood $\left(0.5 \%\right.$ of $\mathrm{BrdU}^{+}$small axonless neurons following BrdU injections in P30 mice). Thus, small axonless neurons are essentially generated perinatally and early postnatally. Their production gradually decreases over the first four postnatal weeks, and is barely detectable in 1-month-old mice.

\section{Synaptic integration of small axonless neurons}

To test whether the receiving dendrite of small axonless neurons also serves as an output structure, i.e., a functional axon, we performed immunostainings with antibodies to VGAT and synaptophysin. To label a larger number of postnatally born small axonless neurons migrating to the cortex, we injected a lentiviral vector expressing GFP in the SVZ of wt pups at P4. In small axonless neurons studied 4 weeks after injection, identified by GFP expression and characteristic morphology, we found synaptophysin and VGAT puncta at various locations on the whole length of the dendritic process (Fig. $8 A, B$ ). We detected on average $7.5 \pm 0.7$ synaptophysin puncta $(n=9)$ and $7.8 \pm 0.7$ VGAT puncta $(n=10)$ per $100 \mu \mathrm{m}$ dendrite of small axonless neuron. (multipolar neurons).
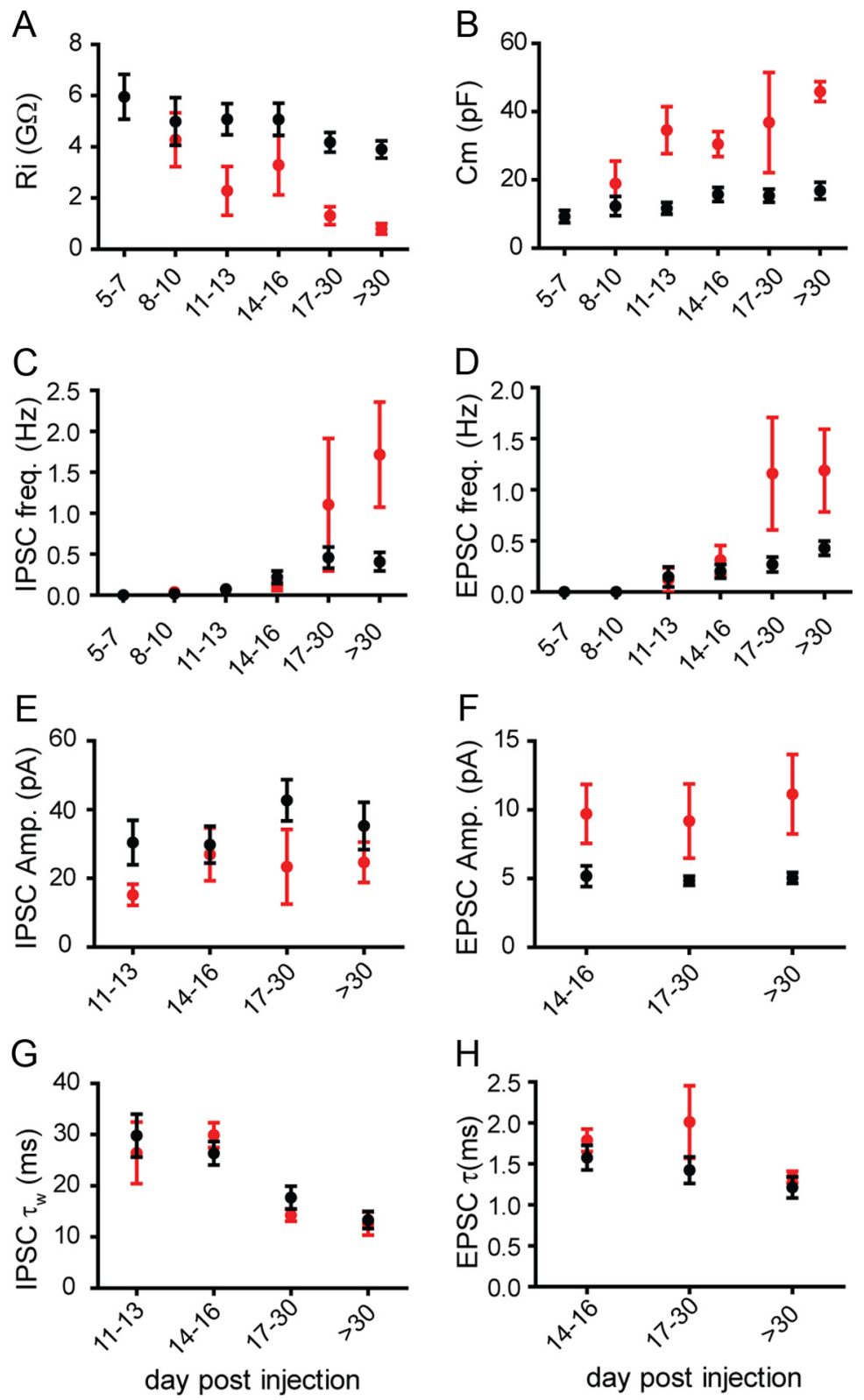

\section{- Small axonless neurons generated at P4 \\ - Multipolar neurons generated at P4}

Figure 5. Time-dependent maturation of passive and synaptic properties in small axonless and multipolar neurons. $\boldsymbol{A}-\boldsymbol{H}$, Input resistance $R_{\mathrm{i}}(\boldsymbol{A})$, cell capacitance $C_{\mathrm{m}}(\boldsymbol{B})$, IPSC frequency $(\boldsymbol{C})$, EPSC frequency $(\boldsymbol{D})$, IPSC amplitude $(\boldsymbol{E})$, EPSC amplitude $(\boldsymbol{F})$, IPSC decay time constant $\tau_{\text {IPSC }}(\boldsymbol{G})$, and EPSC time constant $\tau_{\text {EPSC }}(\boldsymbol{H})$ for small axonless neurons (black dots) and multipolar neurons (red dots) are presented as mean $\pm \mathrm{SEM}$, at different time points after retroviral vector injection in P4 pups. The number of neurons examined for each age category is between 6 and 19 (migrating neuroblasts and small axonless neurons), or between 3 and 6

These data show that small axonless neurons are equipped with the molecular machinery for GABA release in their dendritic tree.

We extended our analysis to the ultrastructural level, to provide evidence for bidirectional connectivity. To this end, we injected a retroviral vector expressing EGFP in newborn cells in P4 wt mice and subsequently analyzed preembedded DAB-stained sections. Small axonless neurons were first identified in semithin sections based on retroviral-based anti-EGFP staining and characteristic morphology. $\mathrm{EGFP}^{+}$unipolar cells lying in deeper cortical layers were subsequently cut out and marked by DAB to 
A
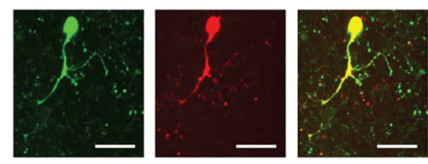

B

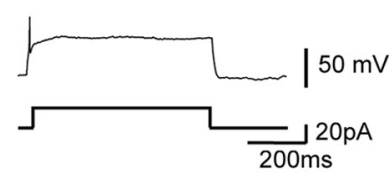

C

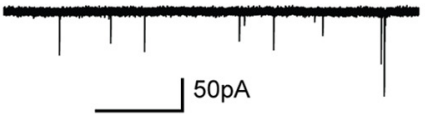

D
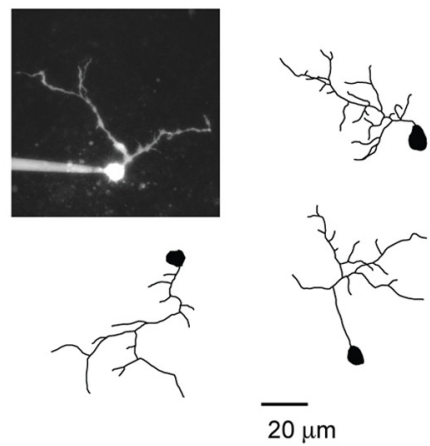

G

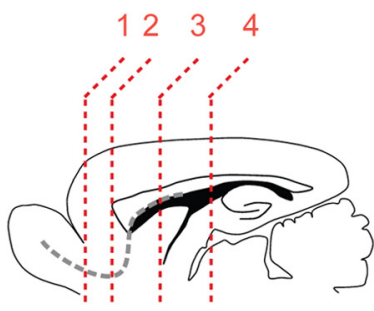

เ1 |

เ2 I

ᄂ3

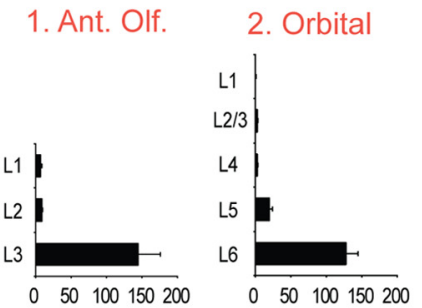

E
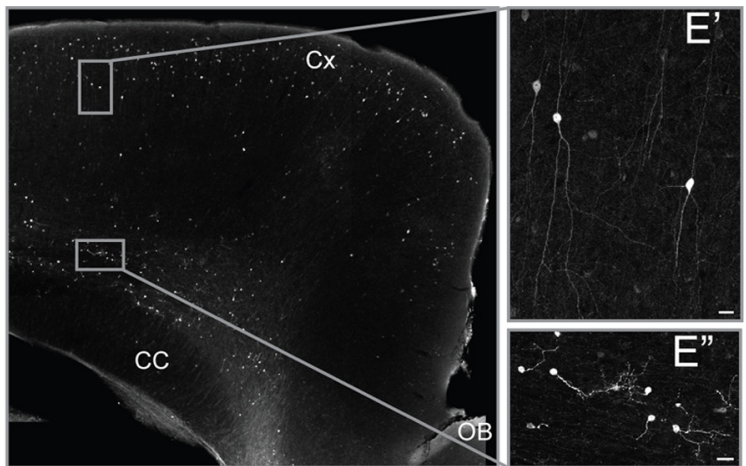

$\mathrm{F}$

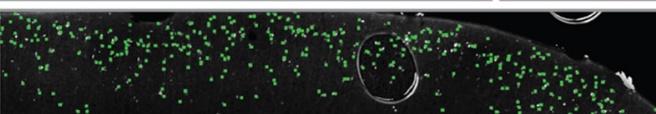

$\mathrm{Cx}$

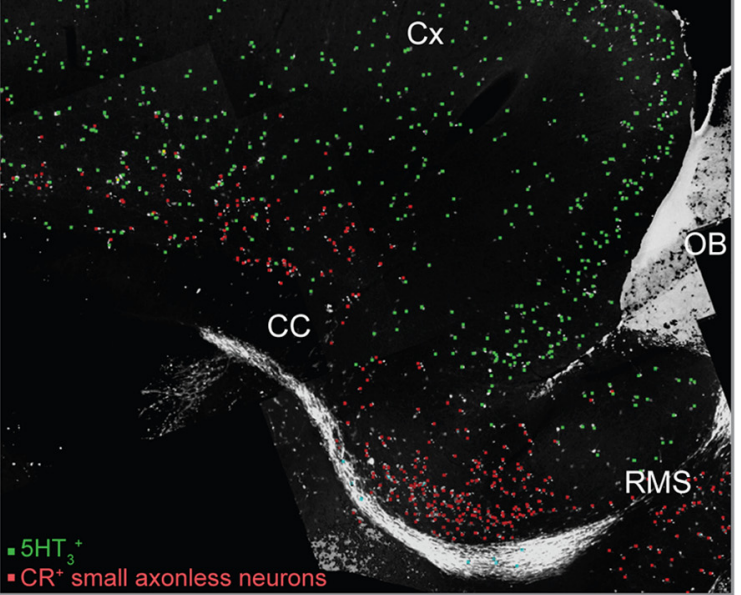

3. Cingulate

4. RSP number of small axonless neurons/coronal section

$\mathrm{H}$

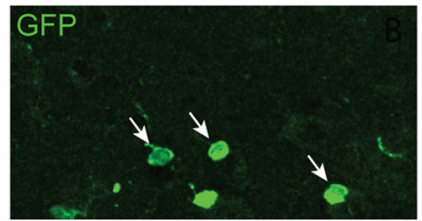

।
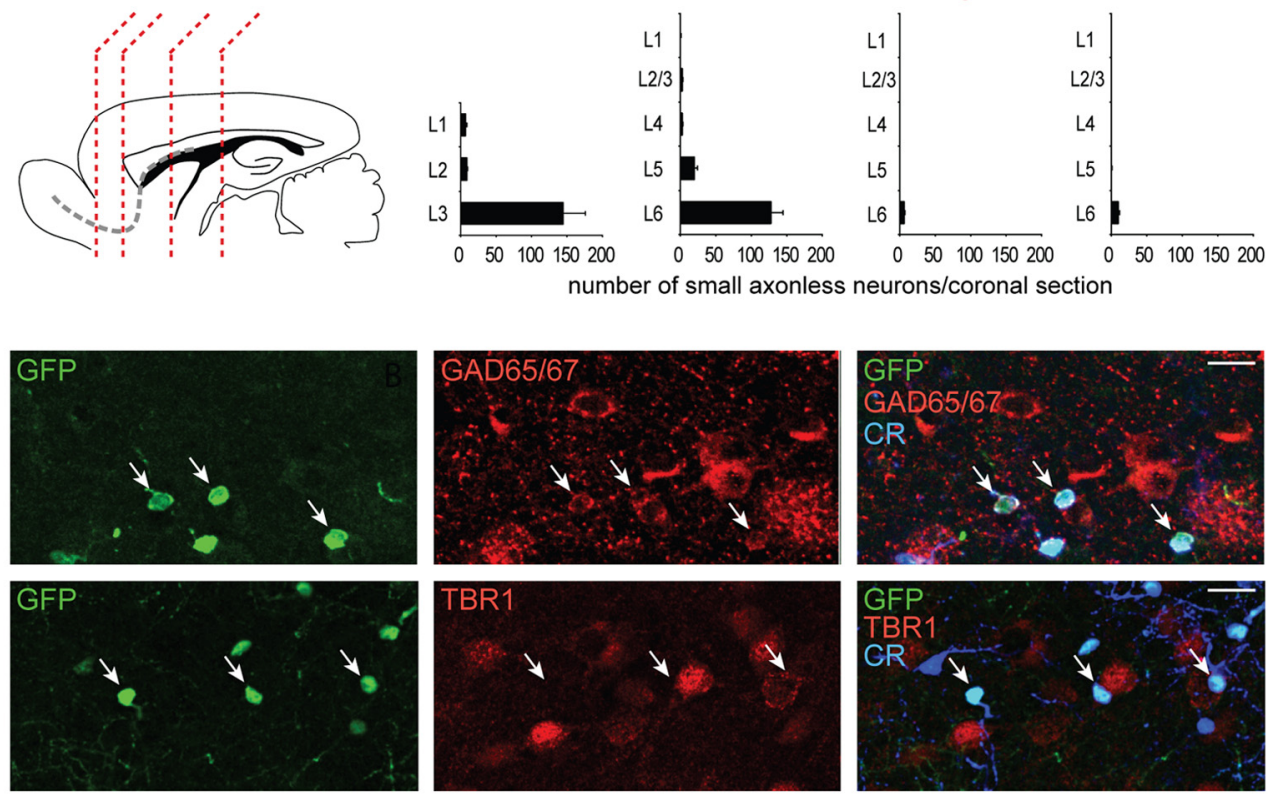

J
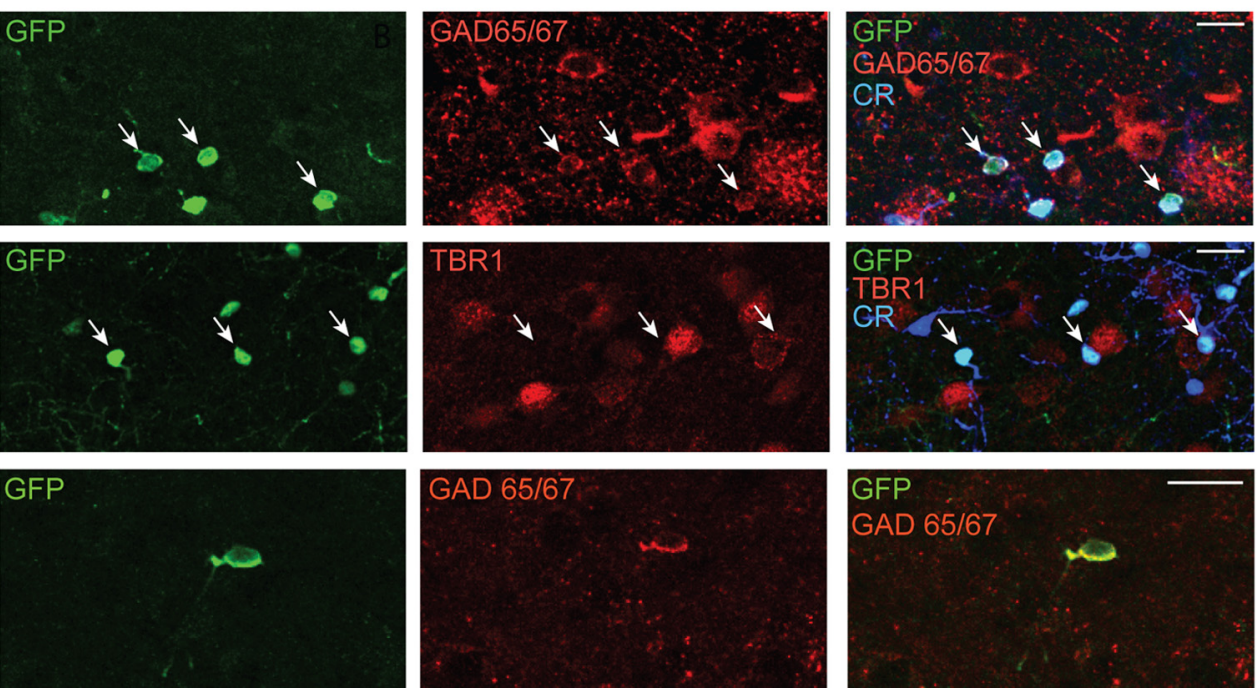

Figure 6. CR and GAD65/67 expression in small axonless neurons. $A$, Confocal image of an EGFP-positive neuron in an acute sagittal slice from a CR-EGFP mouse infected at P4 with a retroviral vector expressing RFP in newborn cells. Left, EGFP fluorescence. Middle, RFP fluorescence. Right, Merged. B, Typical single action potential recorded in current-clamp (top) (Figure legend continues.) 
Table 2. Mediolateral distribution of small axonless neurons

\begin{tabular}{lcl}
\hline Sagittal section examined & $\begin{array}{l}\text { Average number of } \\
\text { (fR-positive small axonless } \\
\text { (from medial to lateral) }\end{array}$ & $\begin{array}{l}\text { CR-positive small } \\
\text { axonless neurons as \% } \\
\text { of the entire } 5 \mathrm{HT}_{3} \text {-EGFP } \\
\text { cortical interneuron population }\end{array}$ \\
\hline 1 & $239 \pm 139$ & $22.2 \pm 1.2$ \\
2 & $269 \pm 83$ & $20.2 \pm 1.1$ \\
3 & $167 \pm 28$ & $18.4 \pm 0.7$ \\
4 & $134.5 \pm 20.5$ & $12.3 \pm 3.0$ \\
5 & $76 \pm 6$ & $7.2 \pm 3.2$ \\
6 & $60 \pm 7$ & $6.4 \pm 2.8$ \\
\hline
\end{tabular}

Cells were counted in six $60-\mu \mathrm{m}$-thick sagittal sections spaced by $300 \mu \mathrm{m}$ along the mediolateral axis; total number of $5 \mathrm{HT}_{3}$-EGFP cells examined, $n=14,399$ cells from 2 mice. Values are given as mean $\pm \mathrm{SEM}$.

form an electron-dense product. Labeled cells appeared characteristically dark on electron micrographs, and synaptic terminals impinging on the soma and dendrite of small axonless neurons were clearly distinguishable (Fig. $8 C$ ). We also observed output synapses characterized by synaptic vesicles in close proximity to two closely apposed membranes in the single dendritic process of small axonless neurons, confirming the presence of dendrodendritic synapses (Fig. 8D).

To study the synaptic output of SVZ-generated neurons in the cortex, we injected a lentivirus encoding light-sensitive channelrhodopsin2 fused to YFP under the control of the synapsin promoter (Zhang et al., 2007) into the SVZ of P4 wild-type pups (Fig. $9 A)$. Three to 6 weeks after viral infection, $\mathrm{YFP}^{+}$small axonless neurons were observed in the deeper layers of the olfactory cortex. Patch-clamp recordings of $\mathrm{YFP}^{+}$small axonless neurons revealed that they responded similarly to somatic depolarization and photostimulation with blue $(473 \mathrm{~nm})$ laser light, namely with a typical single-action potential firing pattern $(n=2)$ (Fig. 9B). We subsequently recorded neurons in the vicinity of YFP ${ }^{+}$small axonless neurons in the orbital or olfactory cortex while applying brief (5-10 ms) pulses of blue light to activate ChR2. In 5 of 126 recorded neurons, photostimulation elicited postsynaptic currents with a success rate of $60.0 \pm 8.4 \%$, an amplitude of $11.3 \pm$ $2.8 \mathrm{pA}$ and a decay time constant of $14.1 \pm 1.5 \mathrm{~ms}$. All five responding neurons had a regular firing pattern reminiscent of glutamatergic pyramidal neurons. Application of GABAzine (10 $\mu \mathrm{M})$ completely blocked light-evoked currents in 4 of 4 cells tested (Fig. 9C).

$\leftarrow$

(Figure legend continued.) elicited by prolonged depolarization (bottom), in the small axonless neuron shown in $A$. C, Spontaneous activity in the same cell recorded in voltage clamp $\left(V_{\text {hold }}=-60 \mathrm{mV}\right)$. D, Morphology of EGFP ${ }^{+}$RFP $^{+}$small axonless neurons in the cortex, $26-42 \mathrm{~d}$ after retroviral injection. Top left, example of a cell filled with the fluorescent dye sulforhodamine B through the patch pipette $(200 \mu \mathrm{M})$. E, CR immunostaining in a wt mouse showing the distribution of (R-positive bipolar and multipolar cells preferentially in upper cortical layers $\left(\boldsymbol{E}^{\prime}\right)$ and $(\mathrm{R}$-positive unipolar, small axonless cells exclusively in lower cortical layers $\left(\boldsymbol{E}^{\prime \prime}\right) . \boldsymbol{F}$, Sagittal overview of an EGFP/CR double immunostaining in a $5 \mathrm{HT}_{3}-\mathrm{EGFP}$ mouse. $\mathrm{CR}^{+}$small axonless cells are indicated with red dots and other $5 \mathrm{HT}_{3}-\mathrm{EGFP}$ interneurons with green dots. $G$, Coronal sections ( $60 \mu \mathrm{m}$ thick) of adult $5 \mathrm{HT}_{3}$-EGFP brains at positions indicated on the left panel were stained for EGFP and CR and counterstained for DAPI to establish the binned distribution of small axonless neurons in cortical layers (bar histograms on the right, mean values \pm SEM, 6 hemispheres from 3 mice). $\boldsymbol{H}-\boldsymbol{J}$, Presence of GAD65/67 but not Tbr 1 in mature small axonless neurons. $\boldsymbol{H}_{\boldsymbol{I}} \boldsymbol{I}, \mathrm{EGFP}^{+}$(green) $\mathrm{CR}^{+}$(blue) small axonless neurons in $5 \mathrm{HT}_{3}$-EGFP mouse cortex colocalize with GAD65/67 ( $\boldsymbol{H}$, red) but not with Tbr1 $(\boldsymbol{I}$, red). $\boldsymbol{J}$, Birthdating experiments showing GAD65/67 expression in a layer VI mature small axonless neuron 7 weeks postinjection of retrovirus expressing GFP. The injection was performed in the SVZ of a 4-d-old wt mouse. All pictures in $\boldsymbol{H}$-J were taken in the orbital or olfactory cortex. Scale bars, 20 $\mu \mathrm{m}$. CC, Corpus callosum; $\mathrm{Cx}$, cortex; $\mathrm{OB}$, olfactory bulb; Hip, hippocampus; Ant, anterior olfactory cortex; Orb, orbital cortex; RSP, retrosplenial cortex.
Finally, to further study the synaptic connectivity of small axonless neurons, we modified a method using tWGA for transsynaptic tracing. tWGA has been used for efficient anterograde tracing to study neuronal connectivity (Braz et al., 2002; Gradinaru et al., 2010). We injected the retroviral vector-GFP-IREStWGA/DsRed (Fig. 9D) in the subventricular zone of P4 mouse pups. Since tWGA/DsRed is a secreted protein, its cellular localization is mainly the ER, Golgi and secretory granules, thus accounting for the punctate appearance in immunostained sections. Twenty-one days after retroviral injection, bright clusters of tWGA/DsRed expression could be observed in the cell body of GFP-positive small axonless neurons, but not elsewhere in the cortex (Fig. 9E). Forty days after retroviral injections, tWGA/DsRed puncta were seen in transsynaptically labeled tWGA/DsRed $^{+}$cells located within a distance of up to $200 \mu \mathrm{m}$ from the small axonless neuron (Fig. 9E').

Together, these results show that small axonless neurons are synaptically wired within local cortical circuits.

\section{Regulation of the number of small axonless neurons by odor exposure}

It is well known that environmental changes cause persistent functional and anatomical modifications in the rodent brain. In particular, housing mice in enriched environments promotes the generation and survival of adult-generated neurons in the dentate gyrus and the olfactory bulb (Kempermann et al., 1997; Rochefort et al., 2002). Small axonless neurons appear to be located predominantly in cortices involved in processing sensory information and more specifically olfactory inputs. Therefore we asked whether raising young mice in an enriched odor environment would regulate the number of small axonless neurons. Wild-type mouse pups (P2-P5) received a single injection of BrdU daily for $4 \mathrm{~d}$, followed by either exposure to different odors for 3 weeks starting at P8 or standard housing (Fig. 10A). To quantify the number of small axonless neurons, we counted $\mathrm{CR}^{+} \mathrm{BrdU}^{+}$cells in both groups. The mean number of $\mathrm{CR}^{+}$ $\mathrm{BrdU}^{+}$small axonless neurons found in the orbital and olfactory cortices was significantly higher in mice that had been kept in an odor enriched environment compared with controls (Fig. $10 \mathrm{~B}$ $D)$. Since odor enrichment was started $3 \mathrm{~d}$ after the last injection of the short-lived BrdU (half-life of $<2 \mathrm{~h}$ ) (Kriss and Revesz, 1962), it is unlikely that the increased cell number resulted from enhanced proliferation of BrdU-labeled small axonless neuron progenitors but rather reflected increased survival. Thus, these results show that a high level of olfactory afferent activity promotes the survival of small axonless neurons in the orbital and olfactory cortex and suggest a role of small axonless neurons in the processing of olfactory bulb outputs.

\section{Maturation of embryonically generated neurons}

To compare the functional maturation of prenatally generated $5 \mathrm{HT}_{3}$-EGFP neurons with that of $5 \mathrm{HT}_{3}$-EGFP small axonless and multipolar neurons born during the neonatal period, we injected the retroviral vector-RFP into the brain of $5 \mathrm{HT}_{3}$-EGFP embryos at E14.5. This allowed the labeling of new cells born at E14.5 with RFP (Fig. 11A). Infected embryos were allowed to develop in utero until birth, and the mice were subsequently killed at different time points from 7 to $41 \mathrm{~d}$ postinfection (d.p.i) to study the development of $\mathrm{EGFP}^{+} \mathrm{RFP}^{+}$cells. These cells were preferentially, but not exclusively, located in layer II-III of the neocortex ( $n=35$ of 50, 8 mice), in agreement with previous reports on the location of $5 \mathrm{HT}_{3} \mathrm{R}$-expressing interneurons (Morales and Bloom, 1997; Férézou et al., 2002). They were either multipolar 

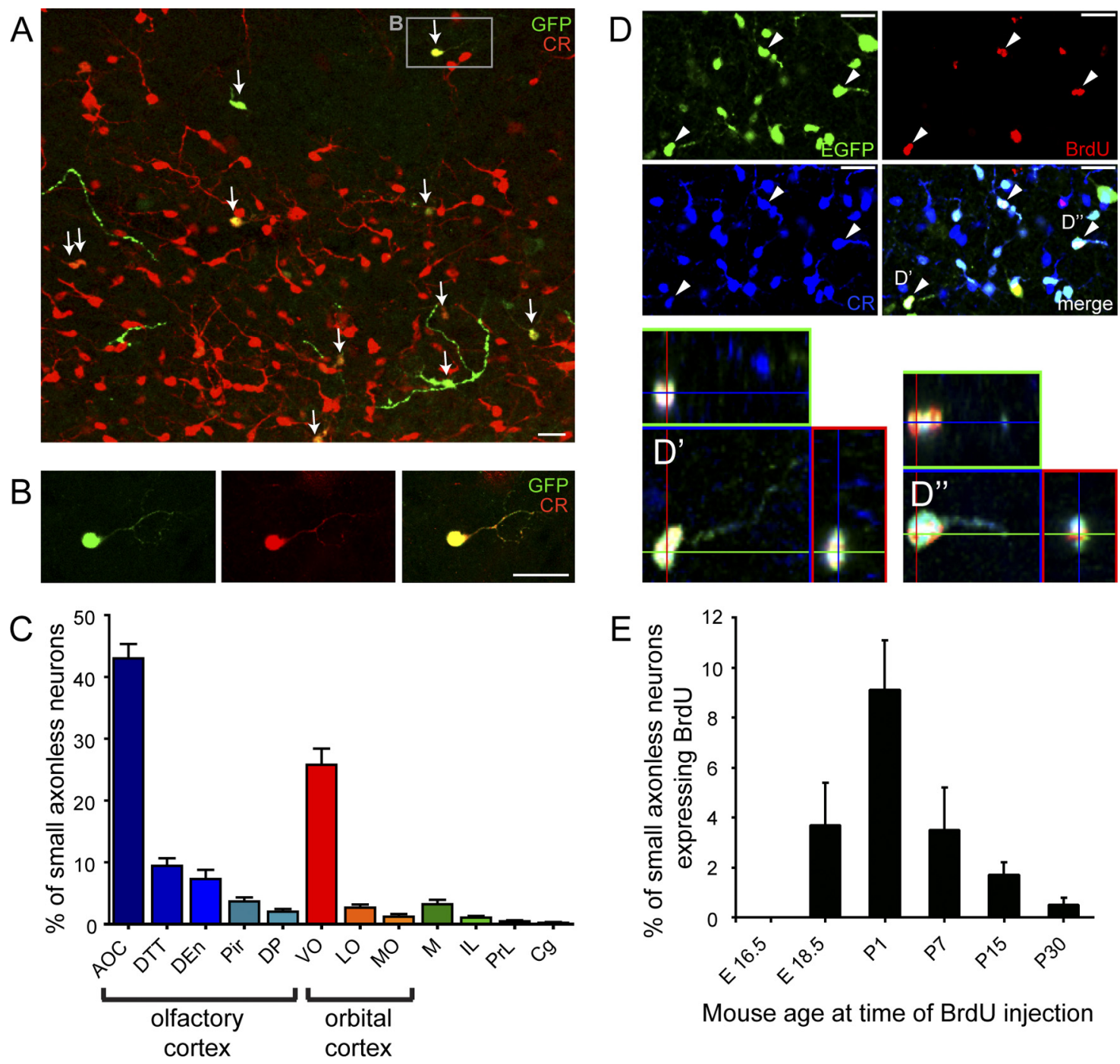

Mouse age at time of BrdU injection

Figure 7. Cortical distribution and time course of generation of small axonless neurons. A lentivirus expressing GFP was injected into the SVZ of P4 mice. After 3 weeks the distribution of GFP-positive cells in the brain was assessed. $A$, Calretinin expression (in red) in lentivirus-infected cells (GFP immunostaining in green) in the orbital cortex. Note the high number of calretininexpressing small axonless neurons in this area. $\boldsymbol{B}$, Example of virus-infected small axonless neurons (enlargement of the area indicated in $\boldsymbol{A}$ ) showing calretinin expression. $\boldsymbol{C}$, Differential distribution of small axonless neurons in the indicated cortical regions. The majority of small axonless neurons reside in olfactory (AOC, DTT, DEn, Pir, DP) and orbital (V0, LO, MO) cortices, 65\% and 30\%,

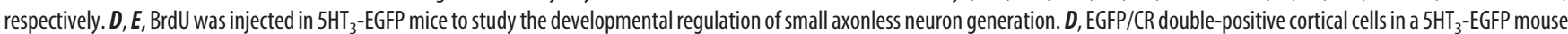
injected with BrdU at P1 coexpress BrdU (arrowheads), indicating that they were generated at P1. $\mathbf{D}^{\prime}, \mathbf{D}^{\prime \prime}$, Magnifications of EGFP/CR/BrdU triple-positive cells. E, Bar histogram showing the percentage of BrdU ${ }^{+}$small axonless neurons following BrdU injections at the indicated mouse age. Scale bars, $20 \mu \mathrm{m}$. AOC, Anterior olfactory cortex; DTT, dorsal tenia tecta; Den, dorsal endopiriform nucleus; Pir, piriform cortex; DP, dorsal peduncular cortex; VO, ventral orbital cortex; LO, lateral orbital cortex; MO, medial orbital cortex; M, motor cortex; IL, infralimbic cortex; PrL, prelimbic cortex; $\mathrm{Cg}$, cingulate cortex.

or bipolar/bitufted (Fig. $11 \mathrm{~B}$ ). We never found small axonless neurons among neurons generated at E14.5. GABAergic PSCs were first detected in $\mathrm{EGFP}^{+} \mathrm{RFP}^{+}$interneurons from neonatal mice at postnatal day 2, $7 \mathrm{~d}$ after in utero viral injection; glutamatergic PSCs were first detected in 9 d.p.i. EGFP ${ }^{+} \mathrm{RFP}^{+}$interneurons. Spontaneous activity progressively increased as neurons matured. Young $\mathrm{EGFP}^{+} \mathrm{RFP}^{+}$cells fired at most a single action potential when stimulated with long depolarizing current injections. Trains of action potentials could be elicited in one neuron aged $9 \mathrm{~d}$, but the majority of cells responded to depolarization with a sustained firing pattern only after 14 d.p.i. Among all neurons with a sustained firing pattern, $86 \%$ (19 of 22) had a regular spiking pattern following slight accommodation (Fig. $11 C$ ). Three of 22 neurons showed a more irregular firing pattern (data not shown), as previously reported for a minority of $5 \mathrm{HT}_{3} \mathrm{R}$-expressing neurons in juvenile rats (Férézou et al., 2002).
Overall, their electrophysiological properties were not distinguishable from postnatally generated multipolar cells of the same neuronal age, indicating that the generation of EGFP ${ }^{+}$multipolar neurons peaks in the embryo but continues in neonatal mice at a low level for a few days after birth, while the generation of small axonless cells occurs by and large postnatally.

\section{Unchanged maturation of grafted embryonic cells}

The characteristic features of postnatally generated small axonless neurons may be sustained by their environment (i.e., the postnatal cortex) or may be cell-inherent. The question then arises whether transplanting prenatally generated $5 \mathrm{HT}_{3}$-EGFP neural progenitors into the postnatal cortical environment alters the fate of these cells. To directly test this, we grafted EGFPexpressing newborn cells from the caudal ganglionic eminence of E14.5 $5 \mathrm{HT}_{3}$-EGFP embryos into the cortical layer VI of P4 wt 

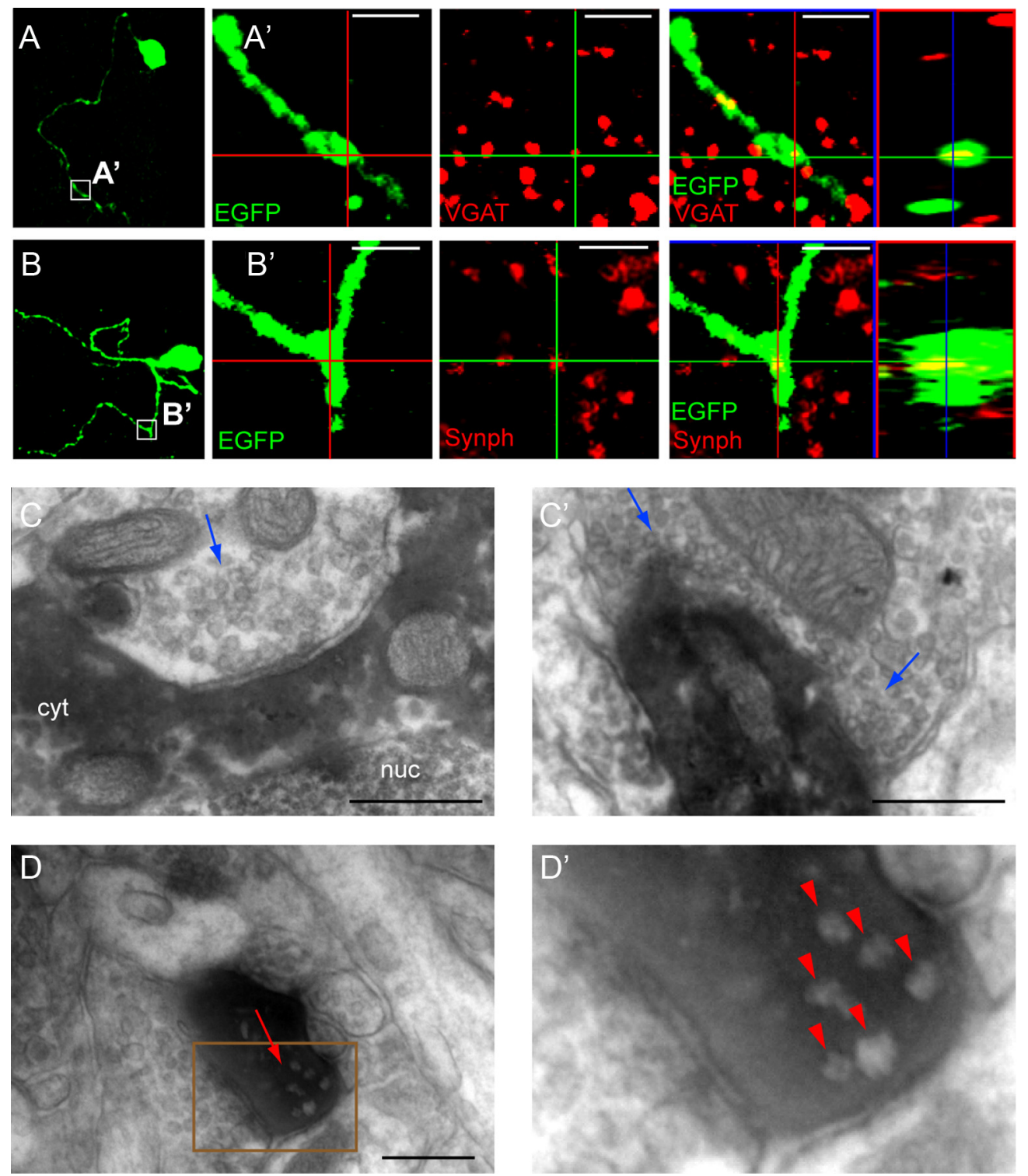

Figure 8. Synaptic input onto and from small axonless neurons. $A, B$, Confocal images of lentivirally labeled small axonless neurons in the cortex of wt mice. $A^{\prime}$, Enlargement of the area boxed in $A$. Immunostainings with antibodies to GFP (green) and the presynaptic protein VGAT (red) show puncta of VGAT expression within the dendrite. Orthogonal views confirm the colocalization of VGAT and GFP. $\boldsymbol{B}^{\prime}$, Enlargement of the area boxed in $\boldsymbol{B}$. Synaptophysin puncta (in red) colocalize with the labeled dendrite (in green), indicating the presence of an essential component of the machinery for GABA release in the dendritic tree. $C_{,} C^{\prime}$, Two representative electron micrographs showing the presence of input synapses onto small axonless neurons. A retrovirus expressing EGFP was injected in the SVZ of wt pups aged P4. Infected cells were marked by anti-EGFP immunostaining and DAB visible as a dark electron dense product in the cell cytoplasm. Synapses (blue arrows) were found on the soma $(\boldsymbol{C})$ and dendritic tree $\left(\boldsymbol{C}^{\prime}\right)$ of small axonless neurons. Pictures are from two cells in two mice. $\boldsymbol{D}, \boldsymbol{D}^{\prime}$, Presence of output synapses in small axonless neurons. $\boldsymbol{D}$, Example showing an output synapse (red arrow) in a DAB-stained process. Vesicles do not take up the DAB product and appear clearer. $\boldsymbol{D}^{\prime}$, Enlargement of the area delineated by a brown rectangle in $\boldsymbol{D}$. Red arrowheads point to presynaptic vesicles at the output synapse. Scale bars: $A, B, 2 \mu \mathrm{m} ; C, D, 250 \mathrm{~nm}$. nuc, Nucleus; cyt, cytoplasm.

pups (Fig. 11D). Consistent with the results of previous studies (Alvarez-Dolado et al., 2006), embryonic neuroblasts grafted at P4 rapidly migrated away from the injection site. They had a widespread distribution in the cortex, although the majority was found in lower cortical layers (V-VI), within $500 \mu \mathrm{m}$ of the injection site ( $n=46$ of 70, 12 mice examined from 6 to $43 \mathrm{~d}$ after transplantation), and they presented a multipolar or bipolar/ bitufted morphology indistinguishable from that of nontransplanted neurons (Fig. 11E). At the earliest time point studied, $6 \mathrm{~d}$ post-transplantation (d.p.t.), they had already lost their migratory morphology and featured multiple processes. Half of them (5 of 10) received spontaneous GABAergic activity. Spontaneous glutamatergic activity emerged later and was first observed at
8 d.p.t. The increase in spontaneous activity during development was paralleled by a maturation of the spiking pattern. Immature grafted cells responded to depolarization with at most a single spike. Trains of action potentials could be generated by prolonged depolarizing steps first in two neurons at 9 d.p.t. and in $84 \%$ of cells ( 26 of 32 ) recorded later than 14 d.p.t. (Fig. $11 F$ ).

The functional maturation of passive electrophysiological properties (input resistance, cell capacitance) and active properties (action potential half-width, maximal firing frequency) was remarkably similar in embryonic $\mathrm{EGFP}^{+}$cells maturing in situ and in embryonic $\mathrm{EGFP}^{+}$cells grafted into the postnatal brain (Fig. 11G). The decrease in the decay time constant of IPSCs was also similar. The only difference was seen in the frequency of 
A

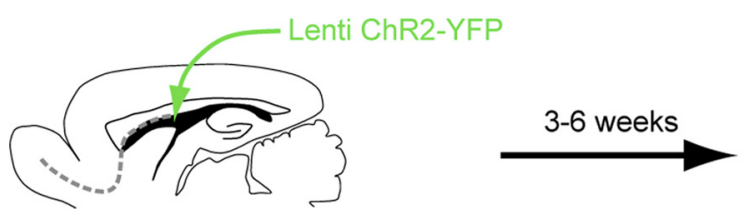

B

Wild-type P4 pup

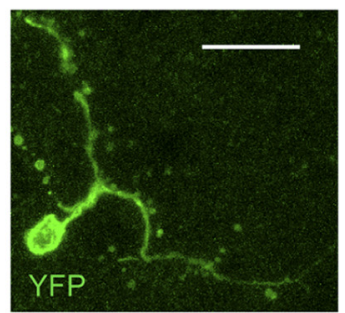

C

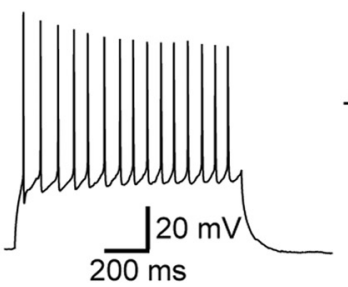

$-70 \mathrm{mV}$

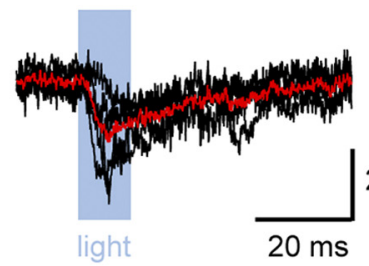

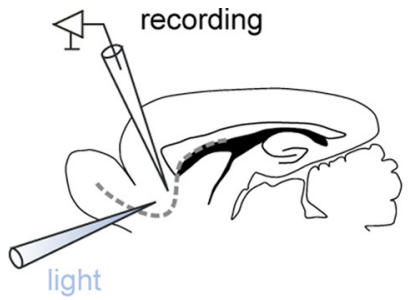

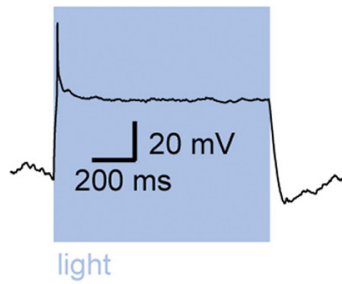

+ GABAzine
$20 \mathrm{pA}$

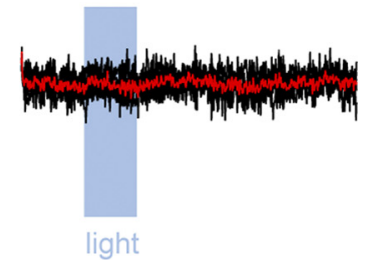

D

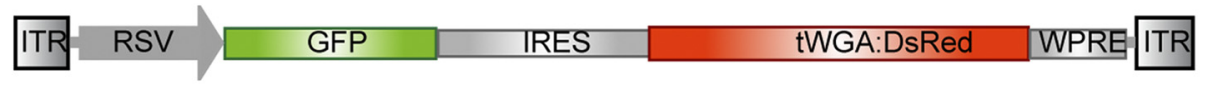

\section{P4 + $21 d p i$}

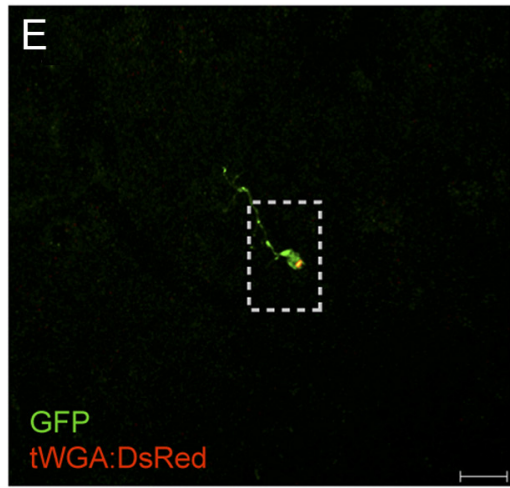

P4 + 40 dpi

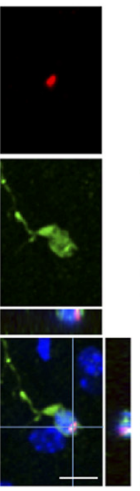

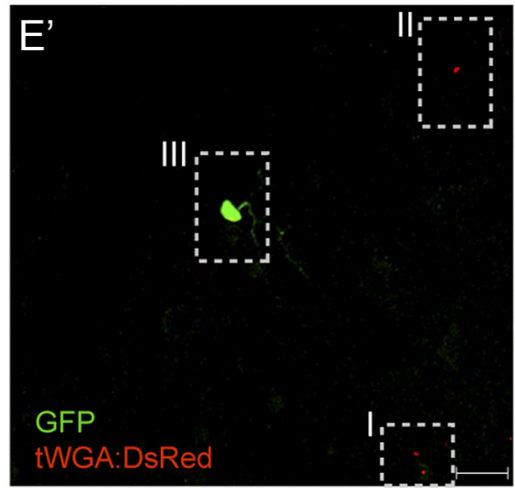

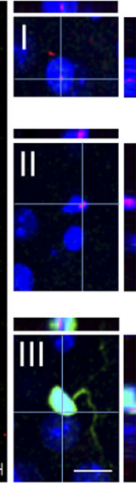

Figure 9. Functional synaptic output of small axonless neurons. $\boldsymbol{A}$, Lentivirus-ChR2-YFP injection and recording protocol. $\boldsymbol{B}$, A YFP-expressing small axonless neuron (left) was recorded in current-clamp and submitted either to somatic depolarization via the patch-clamp pipette (middle) or blue light (right). Note the similar firing pattern in the two conditions. $C$, A cell in the vicinity of a YFP-expressing small axonless neuron was recorded first in current-clamp to obtain its firing pattern (left) and subsequently in voltage clamp while applying brief pulses of blue light (middle). Five superimposed postsynaptic currents in response to blue light are shown (average in red). Postsynaptic currents were abolished by application of GABAzine $10 \mu \mathrm{m}$ (right, 5 traces and average), proving their GABAergic nature. $\boldsymbol{D}$, Construct design for the GFP-IRES-tWGA/DsRed retroviral vector. $\boldsymbol{E}, \boldsymbol{E}^{\prime}$, Transsynaptic labeling with WGA indicating synaptic connectivity. $\boldsymbol{E}$, Confocal image of a GFP-positive small axonless (green) neuron $21 \mathrm{~d}$ after retrovirus injection in the SVZ at P4 showing WGA/RFP expression (red) in the soma. The boxed area is expanded on the right, including DAPI nuclear staining (blue) and orthogonal views showing colocalization of GFP and tWGA/DsRed. E', Same as in E, $40 \mathrm{~d}$ after retrovirus injection. Clusters of tWGA/DsRed (red) are visible in the infected cell and also in the cell soma of neighboring cells, indicating transsynaptic transport. Right panels are magnifications of the boxed areas in $\boldsymbol{E}^{\prime}$, with DAPI nuclear staining (blue) and orthogonal views. Scale bars: $\boldsymbol{E}$ (overview and enlarged area, respectively), 20 and $10 \mu \mathrm{m}$. nuc., Nucleus; cyt, cytoplasm.

spontaneous activity (Fig. $11 \mathrm{H}$ ). Thus, grafted neurons aged $11 \mathrm{~d}$ and more exhibited significantly higher IPSC and EPSC frequencies (IPSCs, $1.42 \pm 0.14 \mathrm{~Hz}$; EPSCs, $0.83 \pm 0.09 \mathrm{~Hz} ; n=32$; age $22.2 \pm 1.5 \mathrm{~d}$ ) than nongrafted ones of a comparable age (IPSCs, $0.68 \pm 0.11 \mathrm{~Hz}$; EPSCs, $0.52 \pm 0.06 \mathrm{~Hz} ; n=42$; age $19.2 \pm 1.7 \mathrm{~d}$, $p=0.0003$ and $p=0.01$, respectively). The higher spontaneous activity in grafted neurons likely reflects the activity of the more mature cortex in which these cells have been ectopically transplanted.

Thus, embryonically and postnatally generated cells seem to be programmed to give rise to distinct neuronal phenotypes whose intrinsic properties mature at a predefined pace, independently of their cortical surrounding. Therefore, small axonless neurons generated postnatally are unlikely to result from a re- 

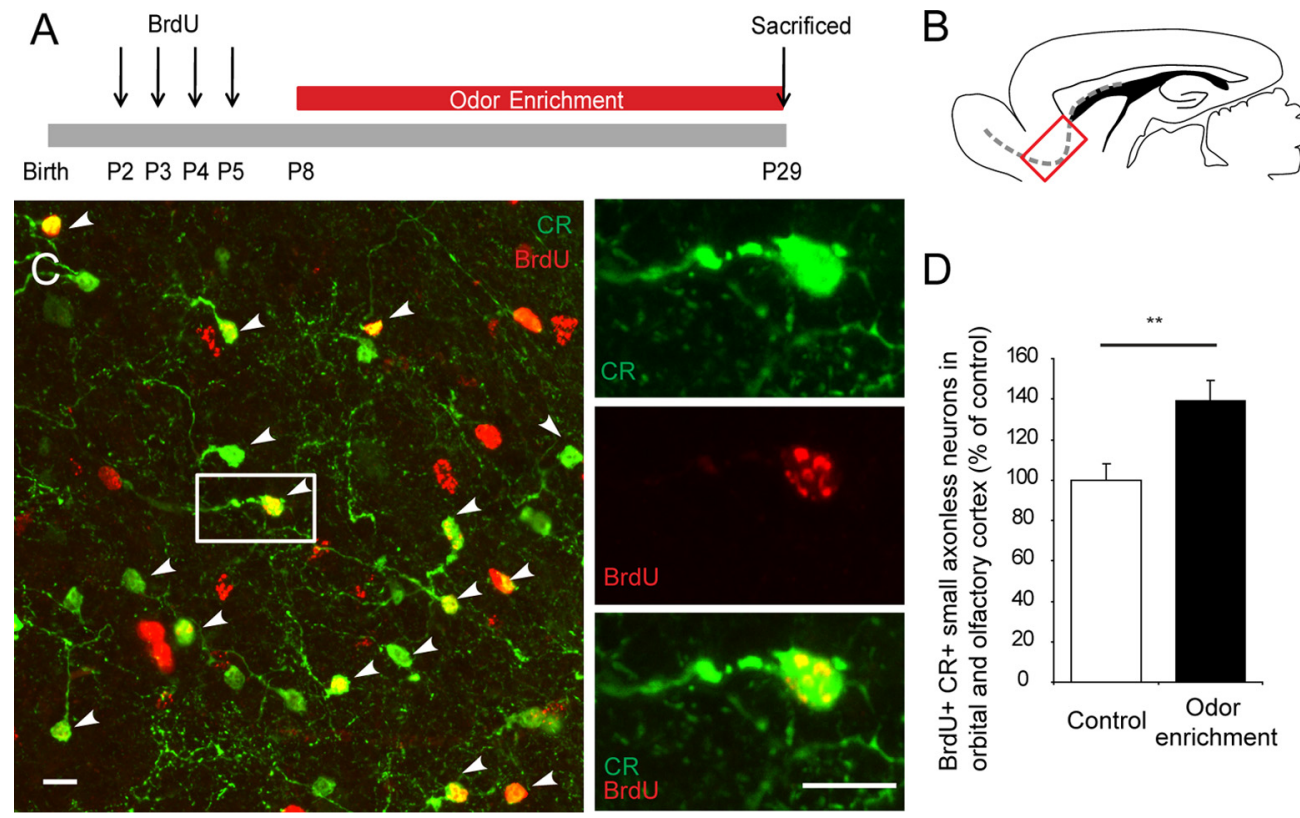

Figure 10. Enhanced number of small axonless neurons following odor enrichment. $\boldsymbol{A}$, BrdU labeling and odor enrichment protocol. $\boldsymbol{B}, S c h e m a t i c$ drawing indicating the area where $C R^{+}$BrdU ${ }^{+}$ small axonless neurons were counted (red rectangle). C, Representative immunostaining with antibodies to CR (green) and BrdU (red) in the orbital cortex of a mouse previously exposed to odor enrichment. White arrowheads point to $\mathrm{CR}^{+} \mathrm{BrdU}^{+}$small axonless neurons. Right panels show an enlargement of the framed area in the left panel. $\boldsymbol{D}$, The number of $C R^{+}$BrdU ${ }^{+}$small axonless neurons in the olfactory and orbital cortices was significantly higher in mice raised in the enriched environment compared with controls, as assessed using Student's $t$ test. ${ }^{* *} p<0.01$. Scale bars, $10 \mu \mathrm{m}$.

tarded development in the postnatal cortex, but are rather a separate class of cortical neurons with distinct morphological, physiological and developmental features.

In summary, we conclude that two distinct types of cortical interneurons are generated in the neonatal SVZ. The minority of them are multipolar neurons and are the tail end of embryonic neurogenesis, since similar cells are produced embryonically. The majority are small axonless neurons, with distinct morphological and physiological characteristics. Unlike most cortical interneurons, they are only produced perinatally and postnatally and communicate with their neuronal partners via dendrodendritic synapses. Their number is regulated by olfactory activity, suggesting that there contribute to the processing of olfactory information.

\section{Discussion}

Our recent study based on immunocytochemical data supported the notion that cells generated postnatally in the SVZ become cortical GABAergic interneurons(Inta et al., 2008). Lack of direct functional evidence, however, did not allow us to conclude that these cells eventually become functionally mature neurons and effectively integrate into the cortical network. We show here, using patch-clamp recordings in neurons from $5 \mathrm{HT}_{3}$-EGFP mice infected with a retroviral vector encoding RFP in the neonatal SVZ, that postnatally generated cortical neurons receive synaptic inputs and fire action potentials. Most of these cells were unipolar, deprived of axon, with delayed maturation of spiking activity. Based on specific anatomical properties, we designated these cells as 'small axonless neurons'. We show, using immunocytochemical markers and electron microscopy, that they express in their dendrites presynaptic terminal markers and form dendrodendritic synapses with other neurons. They constitute a distinct group of calretinin-positive GABAergic interneurons, and are found mainly, though not exclusively, in the deeper layers of the olfactory and orbital cortices. Unlike other cortical interneurons that derive from the embryonic ventral telencephalon, small axonless neurons are generated exclusively perinatally and during the early postnatal period in the subventricular zone.

\section{Unique features of cortical small axonless neurons}

The morphological and physiological characteristics of postnatally born small axonless cells make them unique among cortical neurons. Until now, axonless neurons had been described in the olfactory bulb and the retina, but not in the cortex of rodents. In addition, we demonstrate that small axonless cells undergo a distinct sequence of maturational steps that are different from these of other $5 \mathrm{HT}_{3}$-EGFP cortical interneurons. While in all cell types studied, spontaneous glutamatergic activity appeared later than spontaneous GABAergic activity, as previously reported for many neuronal types in different brain structures, the emergence of spiking activity differed widely. Small axonless cells were able to fire an action potential a week or more after glutamatergic activity had been established, while spiking in other $5 \mathrm{HT}_{3}$-EGFP cells preceded glutamatergic activity and was often concomitant with the establishment of GABAergic activity.

Interestingly, features of postnatally born neurons in the olfactory bulb are in several respects akin to those of small axonless neurons in the cortex. Thus in the olfactory bulb, adult-born granule cells and some adult-born periglomerular cells are axonless (Belluzzi et al., 2003; Kelsch et al., 2008), new granule cells in the olfactory bulb show delayed maturation of spiking activity (Carleton et al., 2003) and adult-born periglomerular neurons fire at most a single action potential upon depolarization (Belluzzi et al., 2003). Small axonless neurons in the cortex are also produced at a time when most bulbar neurons are generated: it was estimated that $41 \%$ of granule cells in the main olfactory bulb are generated during the first postnatal week, 23\% during the second postnatal week and only 14\% thereafter (Hinds, 1968; Bayer, 1983). Axonless neurons in the olfactory bulb make dendrodendritic synapses with their neuronal partners (Shepherd et 
A

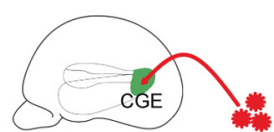

5HT3-EGFP embryo
B

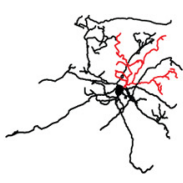

C
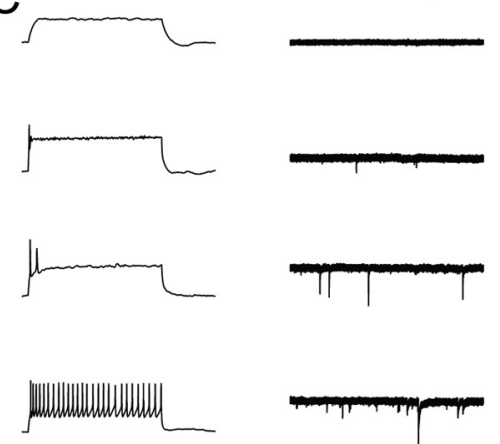

10سلس
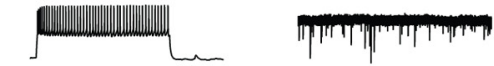

D

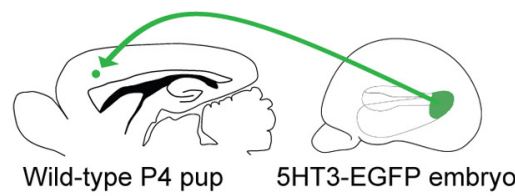

E

F

6-7 dpi

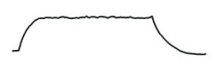

$9 \mathrm{dpi}$
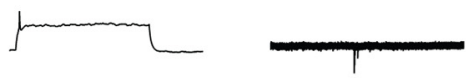

$12 \mathrm{dpi}$

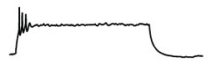

$15 \mathrm{dpi}$
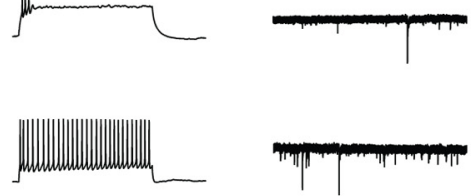

33-34 dpi
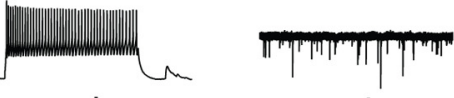

$\frac{\rfloor}{200 \mathrm{~ms}}$
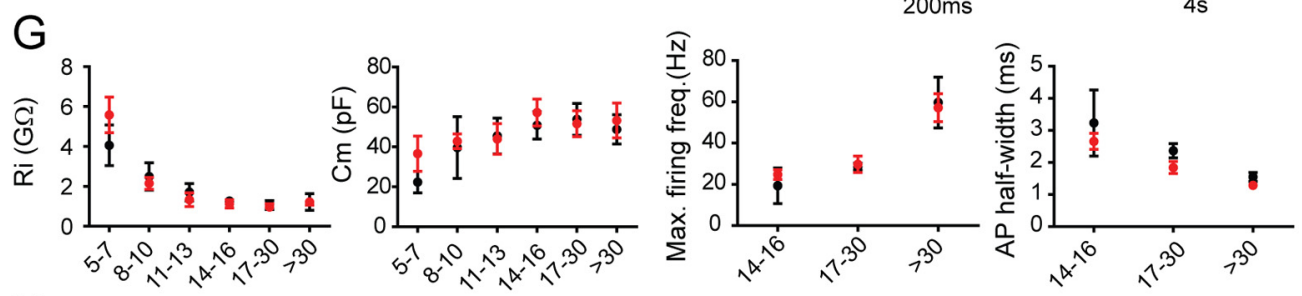

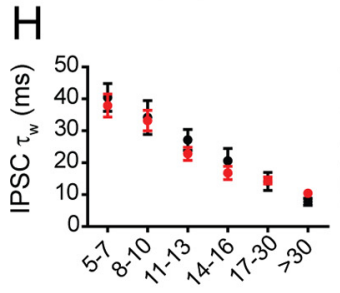

day post injection/graft

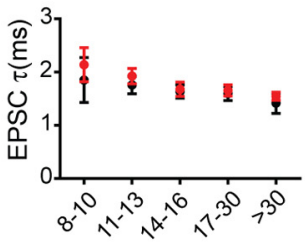

day post injection/graft

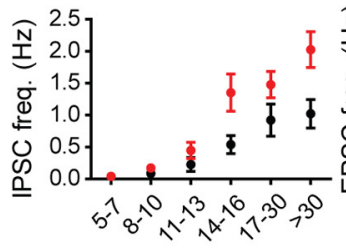

day post injection/graft

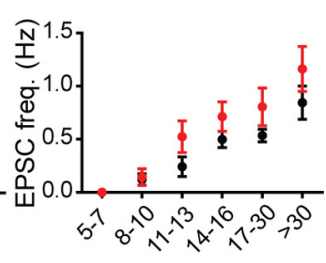

day post injection/graft

- E14.5-born cells developing in situ

- Grafted cells

Figure 11. Unaltered maturation of embryonically born cells grafted into the postnatal cortex. $A, D$, Experimental design. $A$, A retroviral vector expressing RFP was injected in utero in the brain ventricles of $5 \mathrm{HT}_{3}-\mathrm{EGFP}$ embryos at E14.5. D, Newborn $5 \mathrm{HT}_{3}$-EGFP neuroblasts were dissected from the caudal ganglionic eminence of $5 \mathrm{HT}_{3}-\mathrm{EGFP}$ embryos at E14.5 and rapidly grafted into the postnatal cortex (layer VI) of P4 wt pups. $B, E$, Morphological reconstructions (axons in red, dendrites in black) illustrating that the two types of $5 \mathrm{HT}_{3}-\mathrm{EGFP}_{\mathrm{P}}$ interneurons born embryonically (multipolar and bipolar/bitufted) are similar in the two experimental conditions. Normal development in situ $(\boldsymbol{B})$ or after grafting embryonic neuroblasts into the postnatal brain $(\boldsymbol{E}) . \boldsymbol{C}, \boldsymbol{F}$, Current-clamp recordings (left traces) and voltage-clamp recordings (right traces, $V_{\text {hold }}=-60 \mathrm{mV}$ ) illustrate similar maturation of firing pattern and spontaneous activity, respectively, during the course of development in the two experimental conditions ( $\boldsymbol{C}$, born at E14.5; $\boldsymbol{F}$, E14.5 grafted at P4). $\boldsymbol{G}, \boldsymbol{H}$, Electrophysiological properties of embryonically born neurons developing in situ and embryonically born neurons grafted ectopically at $\mathrm{P} 4$ as a function of neuronal age. Passive and active cell properties $(\boldsymbol{G})$ and synaptic properties $(\boldsymbol{H})$ are presented as mean $\pm \mathrm{SEM}$, at different time points after in utero virus injection (black dots) or graft of embryonically generated newborn cells (red dots). The number of neurons examined for each age category is between 6 and 18 except for AP half-width and AP frequency age $14-16$ ( 3 nongrafted), $\tau_{\text {IPSC }}$ age $5-7$ ( 5 grafted, 5 nongrafted) and $\tau_{\text {EPSC }}$ age $8-10$ (5 grafted, 3 nongrafted). AP, Action potential. 
al., 2007). Here we provide ultrastructural and immunochemical evidence that, similarly, in small axonless cortical neurons the dendrite constitutes at the same time release and input site. This is the first description of dendrodendritric synapses in the cortex. In the olfactory bulb, dendrodendritic synapses between granule cells dendrites and mitral cell dendrites are reciprocal, with mitral cells forming gray type I asymmetric synapses onto granule cells, which synapse back onto mitral cells via gray type II symmetric synapses. Here, the presence of a postsynaptic density could not be examined in DAB-stained neurons and therefore the presence of reciprocal synapses could not be ascertained.

\section{Specificity of postnatal migration to the cortex}

In adult rodents, virtually all neuroblasts generated in the SVZ migrate to the olfactory bulb. This migration is contained by "glial tubes" that encapsulates the RMS and guided by blood vessels that parallel the RMS (Lois et al., 1996). Glial tubes are not fully developed in newborn rodents, which may allow a significant proportion of neuroblasts to escape the RMS and randomly integrate into the lower layers of the cortex. However, this would imply that all types of bulbar neurons generated postnatally should be found indiscriminately in the cortex, including granule cells, TH-positive, calbindin-positive and glutamatergic periglomerular cells. On the contrary, we find only two types of cortical neurons born postnatally: (1) the more numerous small, unipolar, CR-expressing cells, in some respects similar to periglomerular cells of the olfactory bulb described previously (Belluzzi et al., 2003) and (2) the less frequent multipolar cells, which do not resemble any known bulbar subtype born postnatally. This argues in favor of a specific cortical migration of distinct types of neuroblasts generated in the SVZ during the early postnatal period.

In the course of embryonic brain development, a large fraction of newborn neurons are eliminated by programmed cell death, which may serve as a way to quantitatively optimize connections of new neurons with their afferent inputs and efferent targets (Buss et al., 2006). In the adult brain, $\sim 70 \%$ of newborn dentate gyrus neurons and half of newborn olfactory bulb neurons undergo programmed cell death within the first month after birth in mice kept in nonenriched environments (Kempermann et al., 1997; Petreanu and Alvarez-Buylla, 2002; Winner et al., 2002). Here, we found cells labeled by early postnatal retrovirus injection and electrophysiologically active at all time points examined after the initial viral injection (up to 10 weeks after injection), showing that neuroblasts migrating to the cortex can survive and remain functionally integrated in cortical networks. However, odor enrichment promoted the survival of small axonless neurons, indicating that a fraction of these neurons undergo cell death in standard housing conditions.

\section{Function of postnatally generated interneurons in the cortex} Cortical neurons generated postnatally are inserted into a network endowed with properties that differ substantially from those encountered by prenatally generated cells. Perhaps not surprisingly, most of these late-generated neurons have specific anatomical and physiological features that distinguish them from prenatally born neurons. However, their function remains to be established. Interestingly, excitability of small axonless interneurons matures slowly, indicating that their functional contribution to the activity of cortical networks is delayed. Therefore, although they are produced relatively early during postnatal development, their actual involvement in cortical information processing occurs in animals that are already adult or almost adult.
The advantage for this slow maturation is not clear. It has been proposed that such delayed excitability in adult-born olfactory bulb granule cells may provide a way to prevent preexisting circuits from functional disruption by newborn cells (Carleton et al., 2003).

Studies on adult-born neurons in the hippocampus and olfactory bulb show that they bring unique properties to mature neural networks. For example, the threshold for inducing long-term potentiation is lower in adult-born granule cells than in older granule cells during a critical period of their development (Schmidt-Hieber et al., 2004; Ge et al., 2007). Similarly, a subset of glutamatergic inputs onto adult-born granule cells of the olfactory bulb show enhanced plasticity during neuronal maturation (Nissant et al., 2009). Hence, cortical neurons born neonatally may provide additional plasticity to the specific areas to which they migrate. Interestingly, small axonless neurons, which represent the vast majority of cortical neurons born postnatally, were mainly found in regions of the cortex associated with the processing of olfactory information, such as the anterior olfactory cortex, dorsal tenia tecta, dorsal endopirifrom nucleus (Shepherd, 2007), and in the orbital cortex. The orbital cortical network also receives sensory inputs from olfactory cortex, taste cortex, somatic sensory association cortex and visual association cortex, and is connected with multisensory areas in the prefrontal and perirhinal cortex (Price, 2007). Functionally, the orbitofrontal cortex is thought to be responsible for higher processing of sensory information and behavioral outcome (Mainen and Kepecs, 2009). Our odor enrichment studies suggest that small axonless neurons are indeed involved in the processing of olfactory inputs. Late-generated cortical neurons may thus maintain in restricted areas of the postnatal neocortex, which are in charge of the higher processing of sensory information, a degree of plasticity that cannot be achieved by preexisting synapses alone.

\section{References}

Altman J, Das GD (1965) Autoradiographic and histological evidence of postnatal hippocampal neurogenesis in rats. J Comp Neurol 124:319-335

Alvarez-Dolado M, Calcagnotto ME, Karkar KM, Southwell DG, Jones-Davis DM, Estrada RC, Rubenstein JL, Alvarez-Buylla A, Baraban SC (2006) Cortical inhibition modified by embryonic neural precursors grafted into the postnatal brain. J Neurosci 26:7380-7389.

Anderson SA, Eisenstat DD, Shi L, Rubenstein JL (1997) Interneuron migration from basal forebrain to neocortex: dependence on Dlx genes. Science 278:474-476.

Bayer SA (1983) ${ }^{3} \mathrm{H}$-thymidine-radiographic studies of neurogenesis in the rat olfactory bulb. Exp Brain Res 50:329-340.

Belluzzi O, Benedusi M, Ackman J, LoTurco JJ (2003) Electrophysiological differentiation of new neurons in the olfactory bulb. J Neurosci 23:10411-10418

Bosman LW, Rosahl TW, Brussaard AB (2002) Neonatal development of the rat visual cortex: synaptic function of GABAA receptor alpha subunits. J Physiol 545:169-181.

Braz JM, Rico B, Basbaum AI (2002) Transneuronal tracing of diverse CNS circuits by Cre-mediated induction of wheat germ agglutinin in transgenic mice. Proc Natl Acad Sci U S A 99:15148-15153.

Brill MS, Ninkovic J, Winpenny E, Hodge RD, Ozen I, Yang R, Lepier A, Gascón S, Erdelyi F, Szabo G, Parras C, Guillemot F, Frotscher M, Berninger B, Hevner RF, Raineteau O, Götz M (2009) Adult generation of glutamatergic olfactory bulb interneurons. Nat Neurosci 12:15241533.

Buss RR, Sun W, Oppenheim RW (2006) Adaptive roles of programmed cell death during nervous system development. Annu Rev Neurosci 29:1-35.

Butt SJ, Fuccillo M, Nery S, Noctor S, Kriegstein A, Corbin JG, Fishell G (2005) The temporal and spatial origins of cortical interneurons predict their physiological subtype. Neuron 48:591-604. 
Caputi A, Rozov A, Blatow M, Monyer H (2009) Two calretinin-positive GABAergic cell types in layer 2/3 of the mouse neocortex provide different forms of inhibition. Cereb Cortex 19:1345-1359.

Carleton A, Petreanu LT, Lansford R, Alvarez-Buylla A, Lledo PM (2003) Becoming a new neuron in the adult olfactory bulb. Nat Neurosci 6:507-518.

Doischer D, Hosp JA, Yanagawa Y, Obata K, Jonas P, Vida I, Bartos M (2008) Postnatal differentiation of basket cells from slow to fast signaling devices. J Neurosci 28:12956-12968.

Dunning DD, Hoover CL, Soltesz I, Smith MA, O’Dowd DK (1999) GABA(A) receptor-mediated miniature postsynaptic currents and alphasubunit expression in developing cortical neurons. J Neurophysiol 82:3286-3297.

Espósito MS, Piatti VC, Laplagne DA, Morgenstern NA, Ferrari CC, Pitossi FJ, Schinder AF (2005) Neuronal differentiation in the adult hippocampus recapitulates embryonic development. J Neurosci 25:10074-10086.

Férézou I, Cauli B, Hill EL, Rossier J, Hamel E, Lambolez B (2002) 5-HT3 receptors mediate serotonergic fast synaptic excitation of neocortical vasoactive intestinal peptide/cholecystokinin interneurons. J Neurosci 22:7389-7397.

Fogarty M, Grist M, Gelman D, Marín O, Pachnis V, Kessaris N (2007) Spatial genetic patterning of the embryonic neuroepithelium generates GABAergic interneuron diversity in the adult cortex. J Neurosci 27:10935-10946.

Ge S, Yang CH, Hsu KS, Ming GL, Song H (2007) A critical period for enhanced synaptic plasticity in newly generated neurons of the adult brain. Neuron 54:559-566.

Gelman DM, Martini FJ, Nóbrega-Pereira S, Pierani A, Kessaris N, Marín O (2009) The embryonic preoptic area is a novel source of cortical GABAergic interneurons. J Neurosci 29:9380-9389.

Gradinaru V, Zhang F, Ramakrishnan C, Mattis J, Prakash R, Diester I, Goshen I, Thompson KR, Deisseroth K (2010) Molecular and cellular approaches for diversifying and extending optogenetics. Cell 141:154-165.

Hinds JW (1968) Autoradiographic study of histogenesis in the mouse olfactory bulb. I. Time of origin of neurons and neuroglia. J Comp Neurol 134:287-304.

Hutcheon B, Morley P, Poulter MO (2000) Developmental change in GABAA receptor desensitization kinetics and its role in synapse function in rat cortical neurons. J Physiol 522:3-17.

Inta D, Alfonso J, von Engelhardt J, Kreuzberg MM, Meyer AH, van Hooft JA, Monyer H (2008) Neurogenesis and widespread forebrain migration of distinct GABAergic neurons from the postnatal subventricular zone. Proc Natl Acad Sci U S A 105:20994-20999.

Kelsch W, Lin CW, Lois C (2008) Sequential development of synapses in dendritic domains during adult neurogenesis. Proc Natl Acad Sci U S A 105:16803-16808.

Kempermann G, Kuhn HG, Gage FH (1997) More hippocampal neurons in adult mice living in an enriched environment. Nature 386:493-495.

Khodosevich K, Seeburg PH, Monyer H (2009) Major signaling pathways in migrating neuroblasts. Front Mol Neurosci 2:7.

Kriss JP, Revesz L (1962) The distribution and fate of bromodeoxyuridine and bromodeoxycytidine in the mouse and rat. Cancer Res 22:254-265.

Laplagne DA, Espósito MS, Piatti VC, Morgenstern NA, Zhao C, van Praag H, Gage FH, Schinder AF (2006) Functional convergence of neurons generated in the developing and adult hippocampus. PLoS Biol 4:e409.

Lledo PM, Merkle FT, Alvarez-Buylla A (2008) Origin and function of olfactory bulb interneuron diversity. Trends Neurosci 31:392-400.

Lois C, Alvarez-Buylla A (1994) Long-distance neuronal migration in the adult mammalian brain. Science 264:1145-1148.

Lois C, García-Verdugo JM, Alvarez-Buylla A (1996) Chain migration of neuronal precursors. Science 271:978-981.

Mainen ZF, Kepecs A (2009) Neural representation of behavioral outcomes in the orbitofrontal cortex. Curr Opin Neurobiol 19:84-91.
Marín O, Rubenstein JL (2003) Cell migration in the forebrain. Annu Rev Neurosci 26:441-483.

Miyoshi G, Hjerling-Leffler J, Karayannis T, Sousa VH, Butt SJ, Battiste J, Johnson JE, Machold RP, Fishell G (2010) Genetic fate mapping reveals that the caudal ganglionic eminence produces a large and diverse population of superficial cortical interneurons. J Neurosci 30:1582-1594.

Morales M, Bloom FE (1997) The 5-HT3 receptor is present in different subpopulations of GABAergic neurons in the rat telencephalon. J Neurosci 17:3157-3167.

Nery S, Fishell G, Corbin JG (2002) The caudal ganglionic eminence is a source of distinct cortical and subcortical cell populations. Nat Neurosci 5:1279-1287.

Nissant A, Bardy C, Katagiri H, Murray K, Lledo PM (2009) Adult neurogenesis promotes synaptic plasticity in the olfactory bulb. Nat Neurosci 12:728-730.

Okaty BW, Miller MN, Sugino K, Hempel CM, Nelson SB (2009) Transcriptional and electrophysiological maturation of neocortical fastspiking GABAergic interneurons. J Neurosci 29:7040-7052.

Pathania M, Yan LD, Bordey A (2010) A symphony of signals conducts early and late stages of adult neurogenesis. Neuropharmacology 58:865-876.

Petreanu L, Alvarez-Buylla A (2002) Maturation and death of adult-born olfactory bulb granule neurons: role of olfaction. J Neurosci 22:61066113.

Price JL (2007) Definition of the orbital cortex in relation to specific connections with limbic and visceral structures and other cortical regions. Ann N Y Acad Sci 1121:54-71.

Rochefort C, Gheusi G, Vincent JD, Lledo PM (2002) Enriched odor exposure increases the number of newborn neurons in the adult olfactory bulb and improves odor memory. J Neurosci 22:2679-2689.

Schmidt-Hieber C, Jonas P, Bischofberger J (2004) Enhanced synaptic plasticity in newly generated granule cells of the adult hippocampus. Nature 429:184-187.

Shepherd GM (2007) Perspectives on olfactory processing, conscious perception, and orbitofrontal cortex. Ann N Y Acad Sci 1121:87-101.

Shepherd GM, Chen WR, Willhite D, Migliore M, Greer CA (2007) The olfactory granule cell: from classical enigma to central role in olfactory processing. Brain Res Rev 55:373-382.

Sugita M, Shiba Y (2005) Genetic tracing shows segregation of taste neuronal circuitries for bitter and sweet. Science 309:781-785.

Toni N, Laplagne DA, Zhao C, Lombardi G, Ribak CE, Gage FH, Schinder AF (2008) Neurons born in the adult dentate gyrus form functional synapses with target cells. Nat Neurosci 11:901-907.

van Praag H, Schinder AF, Christie BR, Toni N, Palmer TD, Gage FH (2002) Functional neurogenesis in the adult hippocampus. Nature 415:1030 1034.

Wichterle H, Turnbull DH, Nery S, Fishell G, Alvarez-Buylla A (2001) In utero fate mapping reveals distinct migratory pathways and fates of neurons born in the mammalian basal forebrain. Development 128:37593771 .

Winner B, Cooper-Kuhn CM, Aigner R, Winkler J, Kuhn HG (2002) Longterm survival and cell death of newly generated neurons in the adult rat olfactory bulb. Eur J Neurosci 16:1681-1689.

Wonders CP, Anderson SA (2006) The origin and specification of cortical interneurons. Nat Rev Neurosci 7:687-696.

Xu Q, Cobos I, De La Cruz E, Rubenstein JL, Anderson SA (2004) Origins of cortical interneuron subtypes. J Neurosci 24:2612-2622.

Zhang F, Wang LP, Brauner M, Liewald JF, Kay K, Watzke N, Wood PG, Bamberg E, Nagel G, Gottschalk A, Deisseroth K (2007) Multimodal fast optical interrogation of neural circuitry. Nature 446:633-639.

Zhao C, Deng W, Gage FH (2008) Mechanisms and functional implications of adult neurogenesis. Cell 132:645-660. 